\title{
A Comparison of Movement Direction-Related Versus Load Direction-Related Activity in Primate Motor Cortex, Using a Two- Dimensional Reaching Task
}

\author{
John F. Kalaska,, Dan A. D. Cohen, ${ }^{1}$ Martha L. Hyde, ${ }^{2}$ and Michel Prud'homme ${ }^{1}$ \\ ${ }^{1}$ Centre de recherche en sciences neurologiques, Départemente de physiologie, Faculté de médecine, Université de \\ Montréal, Montréal, Québec, Canada, H3C 3J7, and 'Department of Veterinary and Comparative Anatomy, Pharmacology \\ and Physiology, College of Veterinary Medicine, Washington State University, Pullman, Washington 99164
}

Shoulder joint-related motor cortex cells show continuously graded changes in activity, centered on a preferred movement direction, during active arm movements in 8 directions away from a central starting position (Georgopoulos et al., 1982). We demonstrate here that many of these cells show similar large continuously graded changes in discharge when the monkey compensates for inertial loads which pull the arm in $\mathbf{8}$ different directions. These load-dependent discharge variations are typically unimodal, centered on one load direction called the cell's load axis, and are often sufficiently continuous, symmetric, and broad as to show a good fit to a sinusoidal curve. A vectorial representation of cell activity indicates that the pattern of load-dependent activity changes in the population forms a signal whose direction is appropriate to compensate for the loads.

The responses of single cells to different combinations of movement and load direction are often complex. Nevertheless, the mean activity of the sample population under any condition of movement direction and load direction can be described reasonably well by a simple linear summation of the movement-related discharge without any loads, and the change in tonic activity of the population caused by the load, measured prior to movement.

The strength of the load-dependent discharge variation differs among cells. Cells can be sorted into 2 phasic and 2 tonic groups that show differing degrees of sensitivity to loads. In particular, it was found that the greater the degree of cell discharge variation associated with different actively maintained limb postures, the greater the activity changes caused by loads. No similar correlation was found for the degree of discharge variation during movement. Preliminary evidence suggests that phasic and tonic cell groups may be spatially segregated in the motor cortex. These observations are consistent with the idea that there exists in the motor cortex activity encoding aspects of movement kinematics, as well as movement dynamics.

\footnotetext{
Received June 28, 1988; revised Oct. 19, 1988; accepted Oct. 24, 1988.

This work was supported by Medical Research Council of Canada Grant MT7693 and an establishment grant from the Fonds de la recherche en Santé de Quêbec (to J.F.K.). M.L.H. was supported by the H. H. Jasper Postdoctoral Fellowship in Neurosciences. We gratefully acknowledge the expert assistance of Richard Bouchoux, Marc Bourdeau, Robert Cartier, Gilbert Duhau, and Jean Jodoin, who built the task apparatus and electronic components, Daniel Cyr and Claude Gauthier for photography, and Feliciana Faraco-Cantin for histology. Giovanni Filosi prepared Figure 1.

Correspondence should be addressed to John F. Kalaska at the above address. Copyright (c) 1989 Society for Neuroscience 0270-6474/89/062080-23\$02.00/0
}

These observations are in agreement with studies of more distal arm joints, showing that the activity of certain motor cortex cells varies with the patterns of muscle activity and output forces required to produce a movement. These experiments extend the description of the control of the direction of movement of a multiple degree-of-freedom joint into the spatial (direction) domain to a greater extent than previously achieved.

One important parameter of movement is its direction. Primates are capable of making a vast range of reaching movements toward targets in different spatial locations. Yet the large majority of neurophysiological studies of motor cortex function have used tasks constrained to one dimension, opposite directions of movement of a single joint (Evarts, 1968, 1969; Thach, 1978; Cheney and Fetz, 1980; Evarts et al., 1983; Fromm, 1983a, b). Observations from these experiments might be sufficient to explain the control of movement at a simple hinge joint, but they are inadequate for multiplc degrcc-of-freedom joints such as the wrist and shoulder. To make more general statements about the control of normal movement by the motor cortex, tasks must be used that involve movements of multiple degree-of-freedom joints in 2 or more dimensions. Furthermore, most previous studies have used movements of distal joints. Differences may exist in the neural control mechanisms for proximal and distal arm movements (Phillips and Porter, 1964; Clough et al., 1968; Lawrence and Kuypers, 1968a, b; Kuypers and Brinkman, 1970; Humphrey, 1979; Lemon, 1979). This study is part of an ongoing investigation of the cortical control of the shoulder joint during whole-arm reaching movements.

A previous report demonstrated that the direction of radially dispersed whole-arm movements away from a central starting position was encoded in the activity of shoulder-related motor cortex neurons as a broadly tuned pattern of discharge, centered on one particular preferred direction (Georgopoulos et al., 1982). Different cells had different preferred directions. The directional tuning of many cells was sufficiently broad, continuous, and symmetric as to show a good fit to a sinusoidal curve. Qualitatively similar observations were made for cell discharge while the monkey actively maintained 9 different arm postures (Georgopoulos et al., 1984a). This broad symmetric tuning implies that each cell contributes a signal whose strength is continuously graded with movement direction, to the motor command for a broad range of movements or postures. It further implies that the information unambiguously encoding the intended direction 
of movement resides in the pattern of discharge of the population of active neurons (Georgopoulos et al., 1982, 1983, 1986, 1988).

Evarts $(1968,1969)$ was the first to study directly whether motor cortex cell activity was related primarily to movement dynamics (i.e., direction and level of forces or torques, etc.) or to movement kinematics (i.e., direction of movement, velocity, etc.). Many subsequent studies of one-dimensional movements have confirmed his observation that the discharge of many motor cortex cells varies with the level of muscle contractile activity, output force or torque, and their temporal derivatives (Humphrey et al., 1970; Humphrey, 1972; Smith et al., 1975; Conrad et al., 1977; Ilepp-Reymond et al., 1978; Thach, 1978; Cheney and Fetz, 1980; Hoffman and Luschei, 1980; Evarts et al., 1983; Fromm, 1983a, b).

The data obtained from the 2-dimensional reaching study of Georgopoulos et al. (1982) did not permit a conclusion as to whether the broadly tuned pattern of movement-related activity of proximal-arm cells was signaling changes in the direction and level of forces, the direction of movement per se, or some combination. However, the contractile activity of shoulder muscles showed similar broad directional tuning (Georgopoulos et al., $1984 a, b)$. It was proposed that the cortical activity could be converted to movement direction-related variations in the level of torque exerted across the shoulder joint at a particular angle determined by the muscle or muscles whose contractile activity is influenced by that cell (Georgopoulos et al., 1983). This angle of torque causes the limb to move along a path corresponding to the cell's preferred direction. The differing preferred directions of different cells would therefore reflect the control of muscle activity exerted across the joint at an angle unique to each cell. The variation of cell activity with movement direction suggests that each cell contributes to the control of movement direction by continually varying the level of muscle contractile activity as a function of the difference between the angle of torque of the cell's peripheral "muscle field" and the net angle of torque required to produce the desired movement. The total torque output required to produce the movement results from the vectorial summation of all the single-cell outputs across the shoulder joint (Georgopoulos et al., 1983).

This hypothesis can be tested by applying loads to the arm in different directions. This causes changes in the level and direction of the net torque output required to make the same movements. Motor cortical neurons should demonstrate continuously graded changes in activity while the monkey compensates for different directions of load. The present experiments were designed to test this prediction.

Although this interpretation has been expressed in terms of the control of a specific parameter of movement dynamics, output torque, it is still not certain what specific aspects of movement dynamics, movement kinematics, or muscle contractile activity are controlled by the motor system (Polit and Bizzi, 1979; Stein, 1982; Hogan, 1984, 1985, 1988; Hollerbach and Atkeson, 1987; Soechting and Ter7uolo, 1988).

Some of the results of these experiments have been reported previously in preliminary form (Hyde and Kalaska, 1984; Kalaska and Hyde, 1985; Kalaska et al., 1985, 1987).

\section{Materials and Methods}

Task apparatus. Monkeys were trained to make visually guided arm movements in 2 dimensions between targets on a target board identical to one used in previous studies (Fig. 1; Georgopoulos et al., 1982;

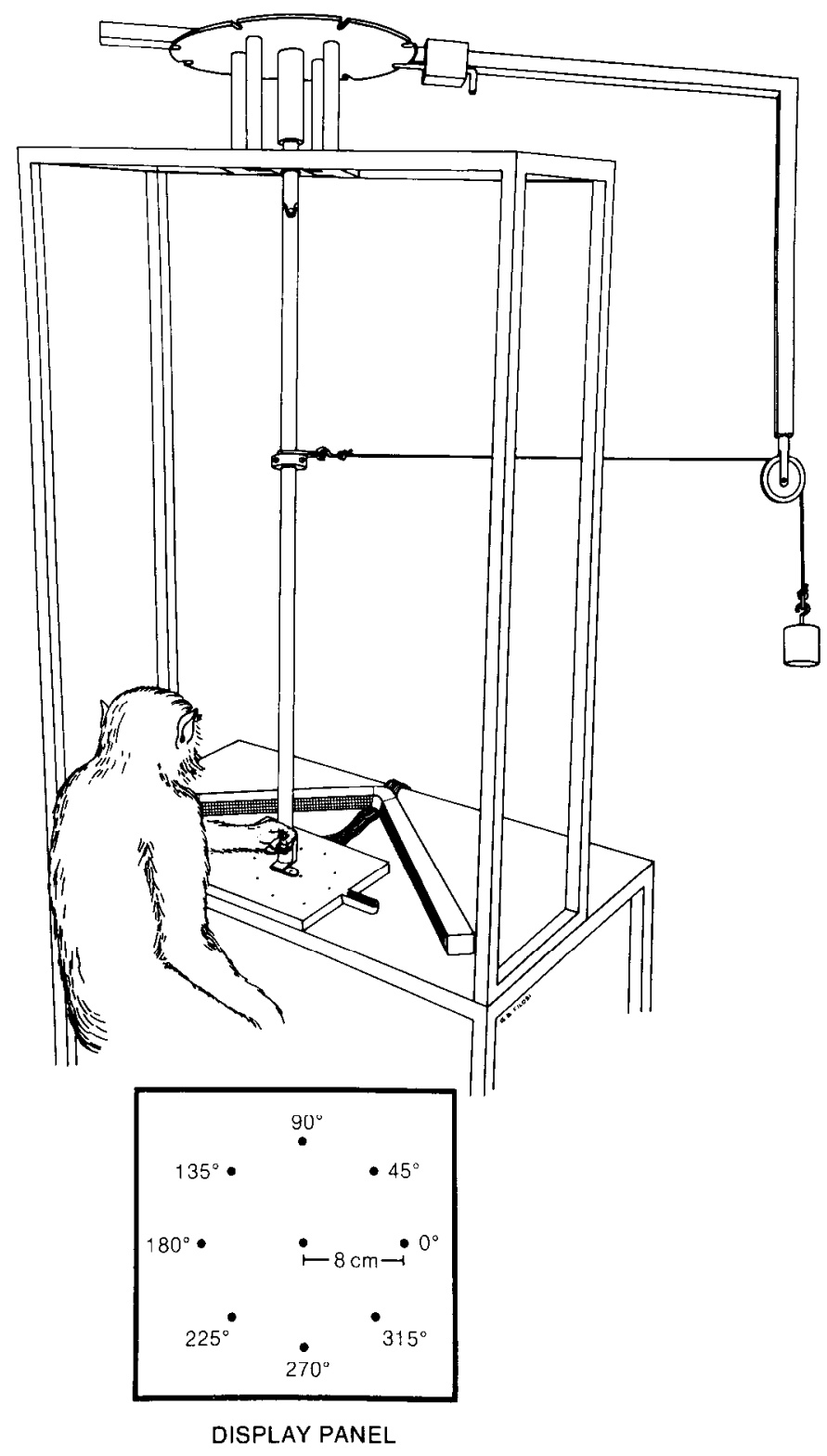

Figure 1. Experimental apparatus used in this study.

Kalaska et al., 1983). It contained 9 LEDs, one at the center and 8 arranged equidistantly on the circumference of a circle of $8 \mathrm{~cm}$ radius.

However, several important modifications have been made to the apparatus (Fig. 1). The target board is horizontal, rather than inclined $15^{\circ}$ toward the monkey. The manipulandum has been changed to a $1-\mathrm{m}-$ long pendulum that is suspended over the target board and can be moved freely above it in 2 dimensions. The $X-Y$ position of the manipulandum is measured to $0.1 \mathrm{~mm}$ resolution 100 times/sec by a sonic digitizer (Science Accessories Corporation model G/P-3) whose energy source is installed at the moving end of the pendulum. A PDP 11/73 minicomputer controls the target sequence of each trial, monitors the monkey's performance, and digitizes and stores all data on-line.

A 1-m-long radial arm and pulley are mounted above the upper end of the manipulandum and can pivot $360^{\circ}$ about its fulcrum point (Fig. 1). By means of this device, an inertial load can be applied to the manipulandum at a point $1 / 3$ the distance from its fulcrum point. The radial arm can be locked into 1 of 8 different positions, corresponding to each of the 8 directions of movement. The load pulls the manipulandum away from the target board toward the pulley. For any given position of the radial arm, the direction of the applied load remains nearly constant wherever the manipulandum is held over the target board, varying by a maximum of $\pm 1.53^{\circ}$ for movements directed toward 


\begin{tabular}{|c|c|c|}
\hline Monkey & Penetrations & Cells \\
\hline 1 & 33 & 77 \\
\hline 2 & 16 & 35 \\
\hline 3 & 10 & 16 \\
\hline 4 & 37 & 95 \\
\hline 5 & 10 & 39 \\
\hline
\end{tabular}

those targets perpendicular to the direction of the applied load. The monkey must exert a continuous counterforce to the handle to restore the manipulandum over the target board in order to make the required movements between the LEDs. In this way, the direction of the displacement trajectory of the arm is partly dissociated from the muscular force or torque trajectory.

The inertial loads used are large enough to produce large changes in EMG activity but small enough to be tolerated by the monkeys for cxtcnded periods of timc. For 3 monkeys, the effective static load was $0.81 \mathrm{~N} \mathrm{~m}$ ( $250 \mathrm{gm}$ weight, 3:1 mechanical advantage). For 2 large males, the load was $1.14 \mathrm{~N} \mathrm{~m}$ (350 gm weight).

Task design. Two spatial parameters were controlled experimentally in this task. The first was the direction of movement and the different actively maintained arm postures prior to and after each movement. The second was the direction of applied loads. The 2 parameters were controlled in a "split-plot" design (Snedecor and Cochran, 1980).

The monkey began each trial by moving the manipulandum over the central LED when it was illuminated. The monkey held its limb in this posture for a variable period of time (mean, $2.0 \mathrm{sec}$; range, $1.2-2.8 \mathrm{sec}$ ). At the end of this period, the central LED was extinguished and 1 of the 8 target LEDs was illuminated at random. The monkey rapidly moved the manipulandum over the new LED and held its arm in that posturc for a further $2 \mathrm{scc}$ bcforc recciving a liquid reward. The 8 peripheral target LEDs were presented in a randomized-block design with 5 replications of each target, for a total of 40 trials.

During each block of 40 trials, the monkey performed the task while encountering 1 of the 9 possible load conditions, either no load (control block) or a load applied continuously in 1 of the 8 directions (load block). A complete data set comprised 9 blocks of 40 trials each. The "split-plot" design derives from the fact that the load-direction parameter was tested across blocks ("plots"), which were "split" into 40 trials to permit the testing of the movement-direction parameter with replications within each block. A split-plot ANOVA was used to evaluate changes in cell activity dependent on either spatial parameter (Snedecor and Cochran, 1980).

One consequence of this split-plot design is that the load-direction parameter is tested sequentially, without replication, over a period of $1-2 \mathrm{hr}$. As a result, any slow temporal variation in cell responsivity across blocks would be statistically indistinguishable from activity changes dependent on the load treatments. To minimize this problem, the following strategy was used. Once a cell was isolated and identified, it was quickly tested with all 8 loads to obtain a qualitative estimate of its task behavior. Blocks of data were then collected, starting with a control block. Next, a load block was collected, followed by another load block in the direction opposite to that of the first. These were followed by a second pair of opposite loads in directions orthogonal to the first pair, and so on. After every 2 or 4 load blocks, a control block was collected to test the temporal stability of cell activity. The exact sequence of load directions varied from cell to cell. The data for a cell were accepted if there were no marked changes in the cell discharge during the repeated control blocks. For analysis, only one of the control blocks was used, usually the block collected after the first 4 load blocks.

Because of the large number of trials required to study one cell, it was usually not possible to collect more than 1 or 2 data sets in each daily recording session.

Data collection. Monkeys were trained until they performed the task under all load conditions at $80-95 \%$ success rates. Monkeys were then prepared for data collection by surgical implantation of a recording cylinder over a trephine hole made in the skull overlying the proximal arm representation of the motor cortex. The cylinder and a head restraint

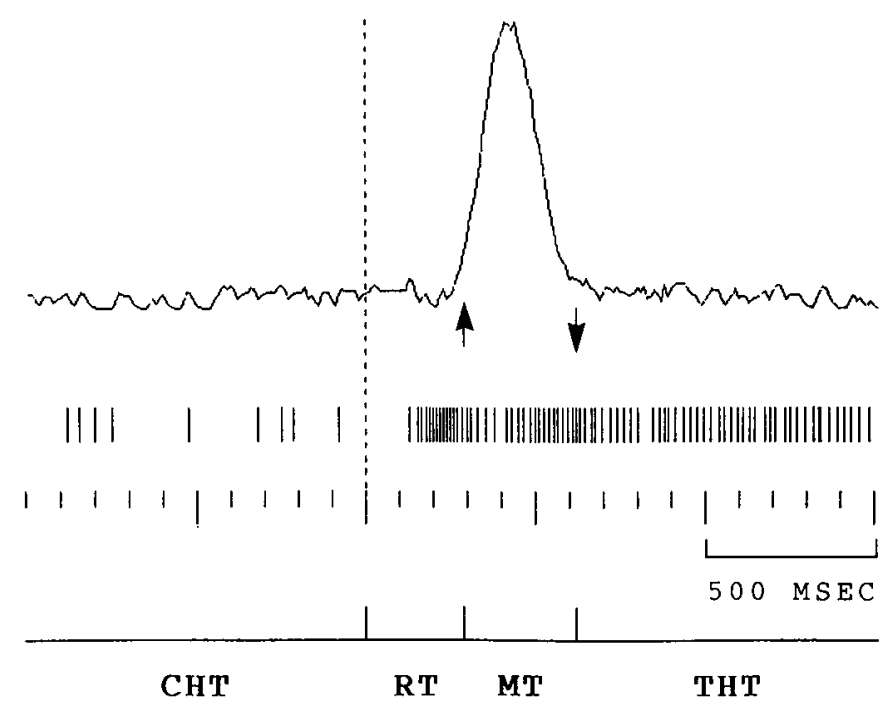

Figure 2. Example of data collected from a single trial. Top trace is the velocity of movement (differential of $X-Y$ position of pendulum). Below it is a series of vertical lines representing the discharge of the cell during the trial. To the left of the vertical dashed line, the monkey is holding the pendulum over the central LED. At the vertical dashed line, the target LED is illuminated. The monkey moves the handle to the I.FD and holds it there. A recursive algorithm determines the onset $(B M)$ and end $(E M)$ of movement. The trial is divided into 4 epochs: center-hold time $(C H T)$, reaction time $(R T)$, movement time $(M T)$, and target-hold time $(T H T)$. Note that only the last part of the CHT and first part of the THT are shown.

device were secured to the skull with neurosurgical screws and acrylic, under ascptic conditions.

Standard recording techniques were used (Georgopoulos et al., 1982). For a cell to be included in the data set, its activity had to vary significantly with the direction of movement in the task, and it had to be related to movements of the shoulder joint or girdle. The normal search procedure was to advance the electrode slowly while the monkey worked, isolating cells that were active in the task. Each active neuron was then tested to determine whether it was related to movements of the shoulder joint or shoulder girdle. Three criteria were used. The first was that the activity of the cell outside of the task was temporally related to movements of the whole arm and to movements of the shoulder joint/girdle in isolation, but not to more distal joints. The second was evidence of responses to passive shoulder movements or palpation of muscles of the shoulder joint/girdle. The third was movement or signs of muscle contractions in the shoulder joint/girdle region in response to lowthreshold microstimulation of the cortex through the recording electrode at the site of the neuron under study. When the consensus of these 3 criteria was that the cell was related to movements of the shoulder joint/ girdle, it was then subjected to detailed quantitative study. The purpose of this procedure was to produce a data sample that was as homogeneous as possible, and comparable to that collected in previous studies (Georgopoulos et al., 1982; Kalaska et al., 1983).

Attempts were made to record cells from all cortical depths, but the requirements of stable isolation over an extended period of time led to a bias for neurons with large-amplitude spikes in intermediate depths of the cortex.

Small electrolytic lesions $(5-10 \mu \mathrm{A}, 5 \mathrm{sec})$ were made in selected penetrations to mark the location of particular cells or to indicate the trajectory of the penetration.

Records of EMG activity during the task were recorded from 3 monkeys. In 2 animals, muscles were implanted percutaneously with pairs of Teflon-insulated $50 \mu \mathrm{m}$ stainless steel wires. In the third monkey, sets of chronically implanted $100 \mu \mathrm{m}$ multistranded stainless steel wires were used. Multiunit EMG activity was amplified, half-wave rectified, and integrated $(0.02 \mathrm{sec}$ time constant), and the EMG envelope digitized on-line at $100 \mathrm{~Hz}$. On a few occasions, single motor units were discriminable in the signal and were recorded like cells. The muscles studied were the deltoids ( 3 heads), pectoralis ( 2 heads), latissimus dorsi, teres 
MONKEY 1

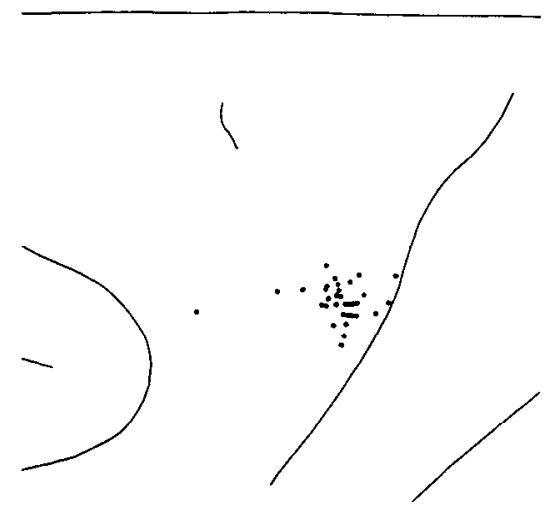

MONKEY 4
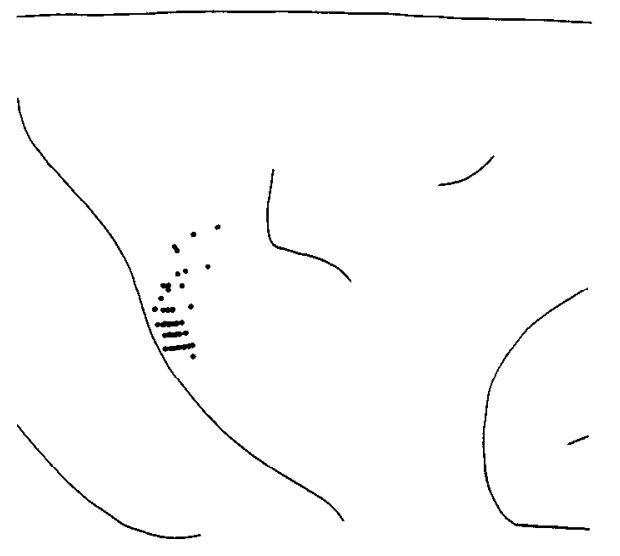

MONKEY 5

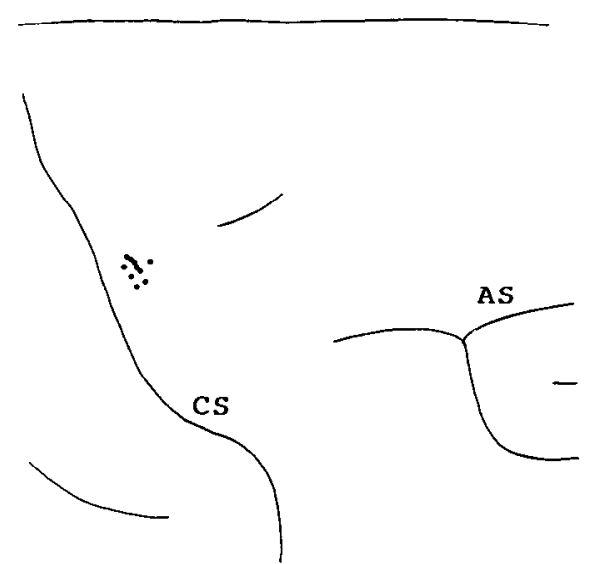

\section{MONKEY 3}
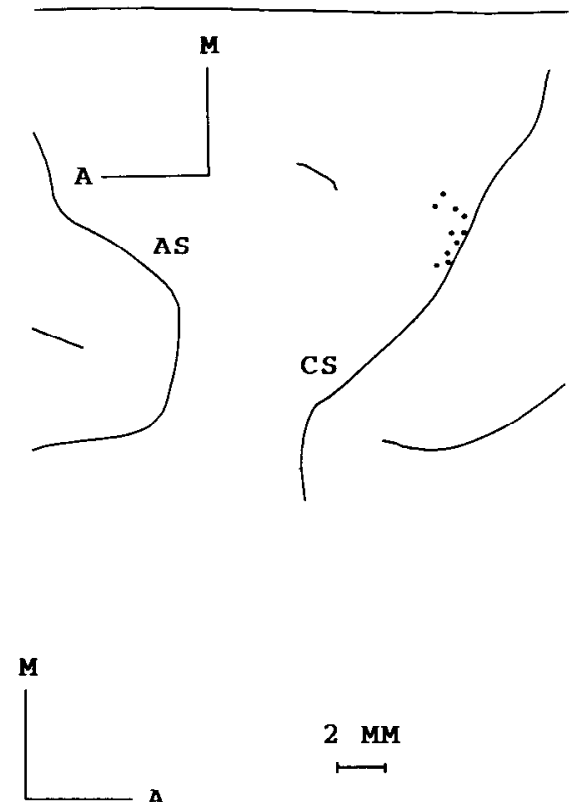

$2 \mathrm{MM}$

Figure 3. Surface maps of the precentral cortex of the left hemisphere of monkeys $1-3$ and the right hemisphere of monkeys 4 and 5 , indicating the location of penetrations from which data were collected for this study. $A S$, arcuate sulcus; $C S$, central sulcus; $A$, anterior; $M$, medial.

major, infraspinatus, supraspinatus, subscapularis, triceps ( 3 heads), biceps ( 2 heads), trapezius ( 2 heads), and rhomboids ( 2 heads).

At the end of the experiment, the monkeys were anesthetized with barbiturates and perfused with buffered saline and formalin. The motor cortex was sectioned to permit localization of the marked penetrations.

Data analysis. Each trial was divided into 4 behavioral epochs (Fig.

2). The velocity of arm movement was calculated by differentiation of the manipulandum $X-Y$ position data. A simple recursive algorithm determined the onset and end of each movement from the velocity trace. Movement onset was defined as the first $10 \mathrm{msec}$ interval during which a significant increase in velocity was observed, provided that the velocities of 3 of the 5 subsequent $10 \mathrm{msec}$ intervals were also significantly above background. The 4 behavioral epochs were (1) Center Hold Time $(\mathrm{CHT})$ from the time the monkey positioned the manipulandum over the central LED to the time the target LED appeared; (2) Reaction Time (RT) from the appearance of the target LED to the onset of movement; (3) Movement Time (MT) from the onset to the end of movement; and (4) Target Hold Time (THT) from the end of the movement to the end of the trial. Data were analyzed for the 4 epochs individually and for the combination $\mathrm{RT}+\mathrm{MT}$.

The basic datum for analysis was the mean discharge rate of the cell during each behavioral epoch or combination. By treating the cell discharge as a quasi-tonic signal, information is lost about details of the complex temporal variation of discharge during any given epoch. However, it was chosen as the most conservative measure of cell activity, showing less intertrial variability than other measures such as peak instantaneous frequency. Analysis of data such as peak instantaneous and median frequency showed qualitatively similar results.

The analysis of movement-dependent discharge variation of a cell during each data block has been described in detail previously (Georgopoulos et al., 1982; Kalaska et al., 1983). Brieffy, an analysis of variance $(F$ test, $p<0.05$ ) identified which cells showed a significant variation of discharge with the direction of movement. Each cell's preferred direction for movement (the center of its movement direction-dependent discharge pattern) was calculated using trigonometric moments (Mardia, 1972). The Rayleigh test $(p<0.05 ;$ Mardia, 1972) identified which cells showed a directional preference. This test is based on a measure of the concentration of the pattern of cell discharge about the preferred direction, and tests whether a cell shows a significant unimodal discharge variation with movement direction, against the null hypothesis of a uniform (i.e., nondirectional) pattern of activity. Finally, a regression of the mean discharge on a sinusoidal curve indicated those cells whose movement direction-related variation was sufficiently continuous and broadly tuned to show a good fit (coefficient of determination $R^{2}>0.7$ ) to a sinusoidal function of the form

$$
y=b_{0}+c_{1} \cos \left(\theta-\theta_{\mathrm{pd}}\right)
$$

where $b_{0}$ is the grand mean of the neural activity across all of the 8 directions of movement predicted by the best-fit movement-direction sinusoid (and thus its offset from 0 ) and $c_{1}$ is the slope of the cosine function (the half-wave amplitude of the sinusoid), $\theta$ is the intended direction of movement, and $\theta_{\mathrm{pd}}$ is the cell's preferred direction of movement.

The analysis of load direction-dependent discharge variation was essentially the same. The split-plot ANOVA identified those cells which showed a significant variation in discharge with the direction of load across data blocks. Each cell's "load axis," the center of its load direction-dependent discharge pattern, was calculated using trigonometric 


\begin{tabular}{|c|c|c|c|c|}
\hline Test & RT & MT & THT & $\mathrm{RT}+\mathrm{MT}$ \\
\hline \multicolumn{5}{|l|}{$F$ test } \\
\hline $\operatorname{sig}(p<0.05)$ & 229 & 244 & 237 & 250 \\
\hline non-sig & 33 & 18 & 25 & 12 \\
\hline$\%$ & 87.4 & 93.1 & 90.4 & 95.4 \\
\hline \multicolumn{5}{|l|}{ Rayleigh } \\
\hline $\operatorname{sig}(p<0.05)$ & 218 & 234 & 217 & 235 \\
\hline non-sig & 11 & 10 & 20 & 15 \\
\hline$\%$ & 95.2 & 95.9 & 91.6 & 94.0 \\
\hline \multicolumn{5}{|l|}{ Sinusoid } \\
\hline $\operatorname{sig}\left(R^{2}>0.07\right)$ & 165 & 177 & 173 & 191 \\
\hline non-sig & 53 & 57 & 44 & 44 \\
\hline$\%$ & 75.7 & 75.6 & 79.7 & 81.3 \\
\hline
\end{tabular}

moments of the variation of the grand mean discharge across load blocks. The Rayleigh test identified those cells whose variation in discharge with load direction showed a significant unimodal deviation from uniformity. Finally, a sinusoidal regression indicated those cells whose load direction-dependent discharge variation showed a good fit to a sinusoidal function of the form

$$
y=b_{0}+c_{1} \cos \left(\phi-\phi_{13}\right),
$$

where $b_{0}$ is the grand mean of the best-fit load-direction sinusoid and $c_{1}$ its half-wave amplitude, $\phi$ is the direction of applied load, and $\phi_{1 \mathrm{a}}$ is the cell's load axis.

Simple measures of the strength of movement direction- and load direction-dependent discharge variation are the movement-direction range and the load-direction range. These are defined as the difference between the strongest and weakest mean discharge observed among the 8 directions of movement or load, during a particular behavioral epoch These measures can be used to test whether there is a relation between the intensity of discharge of a cell during movement, during postural maintenance, and during load compensation. To study this quantitatively, while normalizing for the differing level of discharge among cells, we devised 2 other useful measures of cell activity, the position/movement index and load/movement index. The position/movement index is the log of the ratio of the movement-direction range recorded during THT to that during RT, MT, or RT + MT, all recorded in the control block. This gives a measure of the strength of the signal contributed by a cell for active postural maintenance as a ratio of that for movement in different directions. The load/movement index is the log of the ratio of the load-direction range recorded during CHT in load blocks, and the movement-direction range during $\mathrm{RT}, \mathrm{MT}$, or $\mathrm{RT}+\mathrm{MT}$ in the control block. This gives a measure of the strength of the signal contributed by a cell during load compensation before movement relative to that for movement without external loads. The log of the ratio was chosen to normalize the highly skewed distribution inherent in ratios.

\section{Results}

\section{Data base}

Usable data sets were collected from 262 cells (Table 1), during 106 penetrations in the motor cortex of 5 hemispheres in 5 adolescent monkeys ( 3 male Macaca fascicularis, $2.5-3.5 \mathrm{~kg}$, and 2 malc Macaca mulatta, $4.5-5.5 \mathrm{~kg}$ ). These animals also were used for other studies to be described in subsequent articles. The majority of penetrations were confined to the cortex in the anterior bank of the central sulcus and at its crown (Fig. 3). Only a few were made more than $3 \mathrm{~mm}$ rostral to the sulcus. The penetrations were also confined to the shoulder representation located medial to the large distal arm representation (Kwan et al., 1978).
Data were collected from the contralateral cortex while monkeys 1-3 used their right arm. Monkeys 4 and 5 used their left arm, and these results were normalized to the right arm by a mirror-image inversion of the data about the $90^{\circ}-270^{\circ}$ axis.

\section{Variation of cell discharge with movement direction}

As described previously (Georgopoulos et al., 1982, 1983), many cells related to shoulder movement were broadly tuned for movement direction in the control blocks. Cell activity typically varicd in a continuously graded fashion with movement direction, centered on a preferred direction (Fig. 4). The distribution of preferred directions of the data sample included the entire range of movement directions away from the central start position (data not shown).

All 262 neurons showed a significant variation of activity during at least one of either RT, MT, or THT, and frequently during all 3 epochs (Table $2, F$ test, $p<0.05$; a significant variation was an a priori criterion to study the cell). For most of these (91-95\% in different epochs), the modulation varied unimodally with direction (Table 2 , Rayleigh test, $p<0.05$ ). Finally, $75-81 \%$ of the unimodally tuned cells showed a good fit to a sinusoid in different epochs $\left(R^{2}>0.7\right)$. Cells that passed the Rayleigh test but showed poor regressions were usually too skewed or sharply tuned with movement direction to show a good fit to a sinusoid. The few cells that failed the Rayleigh test also generally had poor regression fits since most showed a bidirectional or erratic pattern of discharge with movement direction during that behavioral epoch. Thus, the large majority of shoulder-related cells showed significant unimodally tuned activity changes with movement direction, which was approximately sinusoidal for a somewhat smaller subset of cells.

\section{Variation of cell discharge with load direction General description}

The cell illustrated in Figure 4 had a preferred direction oriented at $122^{\circ}$ toward the upper-left quadrant, that is, for movements of flexion, adduction, and inward rotation of the right shoulder joint. A load directed at $315^{\circ}$, i.e., approximately opposite to the cell's preferred direction for movement, produced a marked increase in its discharge in the task (Fig. $5 A$ ). The most striking change from the control condition was a large increase in the overall level of activity of the cell. For instance, the tonic rate during CHT increased from $8.4 \mathrm{imp} / \mathrm{sec}$ in the control block to $32.4 \mathrm{imp} / \mathrm{sec}$, as indicated by the radius of the circle in the polar plot of Figure $5 \mathrm{~A}$. The cell continued to show graded changes in activity with movement direction, superimposed on the increased tonic rate. In contrast, a load at $135^{\circ}$, approximately corresponding to the cell's preferred direction, resulted in a sharp reduction in cell discharge in the task, again most evident by the reduction in CHT tonic rate to $0.5 \mathrm{imp} / \mathrm{sec}$ (Fig. $5 B$ ).

The responses of the cell under all 9 load conditions are summarized in Figure 6A. The discharge of the cell in the control block (Fig. 4) is represented by the polar plot at the center of the figure. The remaining 8 polar plots illustrate the response of the cell during the 8 load blocks, with the position of the polar plot corresponding to the direction in which the handle is pulled away from the center of the target panel by the load. Thus, the "opposing" load of Figure $5 A$ is at the lower right, $315^{\circ}$, and that of the "assisting" load at $135^{\circ}$ at the upper left. The loads produced large changes in cell activity that were con- 

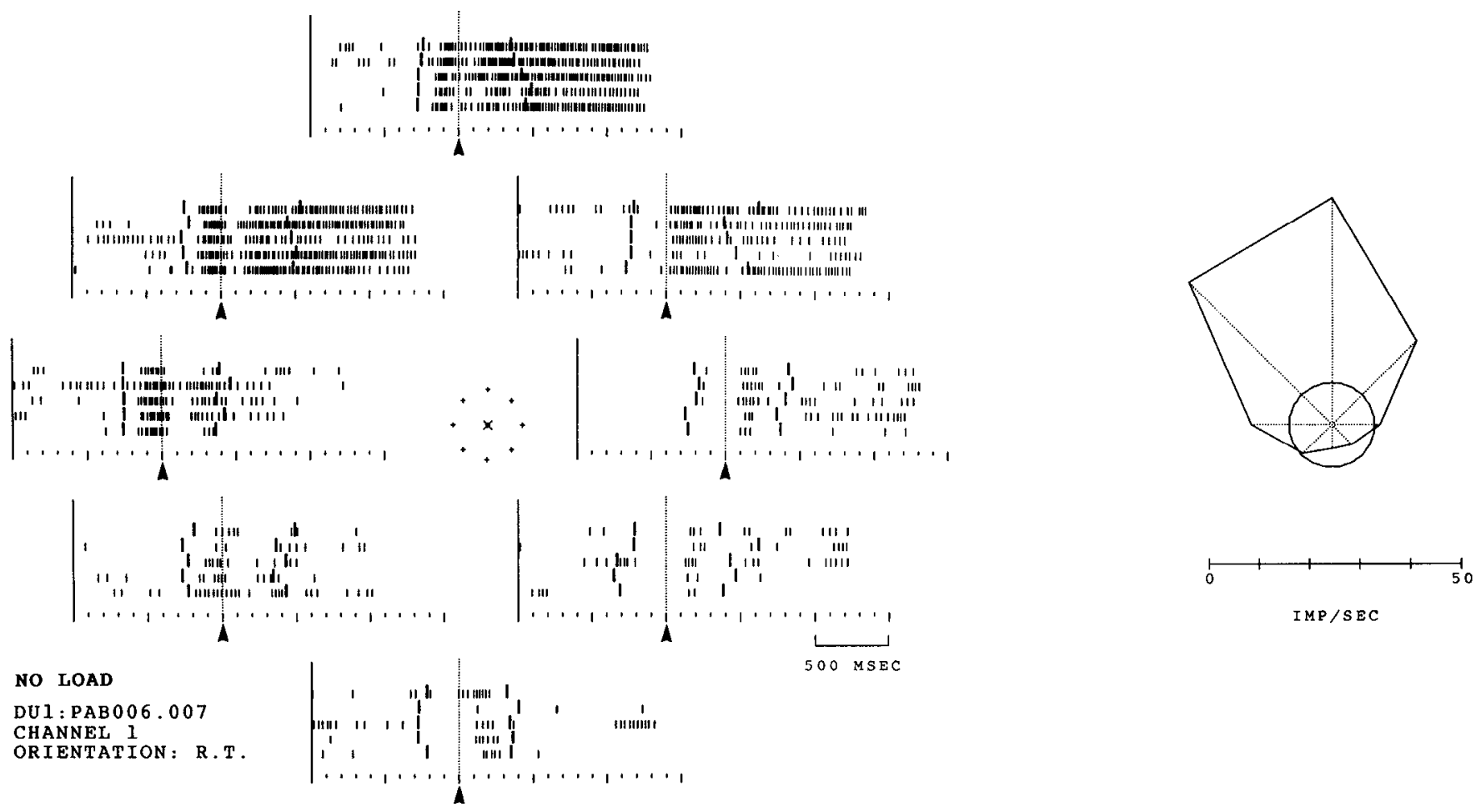

Figure 4. Discharge pattern of a shoulder joint-related area 4 cell in the control block, displayed in raster (left) and polar-plot form (right). Eight rasters illustrate cell activity during 5 trials to each of the 8 targets. Raster position corresponds to the direction of movement away from the center LED. Data are oriented to the onset of movement (arrow below each raster). The heavy line to the left of the arrow in each raster line indicates the time the target LED appeared, and the heavy line to the right of the arrow indicates the end of movement. Note that only the last part of the CHT and the first part of the THT are shown. The radius of the circle in the polar plot corresponds to the grand mean of the tonic rate during CHT for all 40 trials of the control block, while the length of each axis of the polar plot represents the mean discharge during the epoch RT + MT, for 5 replications of the corresponding direction of movement. The cell shows continuously graded changes in activity with different directions of movernent, centered on movements to the upper left. The cell's activity during the epoch RT + MT showed an excellent fit $\left(R^{2}=0.94\right)$ to a sinusoidal curve of the form $y=20.80+18.15 \cos \left(\theta-\theta_{\mathrm{pd}}\right)$, where $\theta_{\mathrm{pd}}$ was the cell's preferred movement direction, $122^{\circ}$.

tinuously graded with the direction of the load. This load direction-dcpendent discharge variation showed an excellent fit to a sinusoid (coefficient of determination, $R^{2}=0.92-0.98$ for different epochs), and was centered on one direction of load, called the cell's load axis (Fig. 6A, dot-dashed line). The load axis was approximately opposite to the cell's preferred movement direction (Fig. 6A, dashed line). Figure 6, $B, C$, emphasizes the fundamental qualitative similarity of the cell's relation to movement direction (Fig. $6 \mathrm{~B}$ ) and to load direction (Fig. 6C). Cell discharge tends to vary as a cosine function of the difference between the cell's preferred direction and the intended movement direction (Fig. $6 \mathrm{~B}$ ), and as a cosine of the difference between its load axis and the direction of applied load (Fig. 6C). For this particular cell, both spatial parameters also produce quantitatively similar activity changes.

Continuous gradation of discharge with the direction of load was seen for many cells in the task. However, different cells showed this effect to varying degrees (Fig. 7). Many cells were strongly affected by the direction of applied loads (Fig. $7 \mathrm{~A}$ ). Others were somewhat more moderately affected (Fig. $7 B$ ). Still others were strongly related to movement direction but showed weak changes in discharge under different load conditions (Fig. $7 C$ ). The differing load sensitivity of cells did not suggest the existence of distinct cell types. Rather, there appeared to exist a continuum of differing sensitivity, with the examples in Figure 7 illustrative of cells at different points along this continuum.

\section{Quantitative analysis}

The task was divided into epochs during which the monkey held its arm in different postures over the LEDs (CHT and THT) and epochs during which the monkey initiated and executed a movement between the LEDs (RT and MT).

While holding the pendulum over the central starting position $(\mathrm{CHT}), 248 / 262$ (94.7\%) of the cells showed significant variations in tonic discharge while the monkey compensated for loads in different directions (Table 3, split-plot ANOVA, $F$ test, $p<$ 0.05 ). Of those 248 cells, the load direction-dependent discharge variation of 164 cells $(66.1 \%)$ showed a significant unimodal deviation from uniformity centered on a load axis (Table 3, Rayleigh test). Finally, for the large majority of these latter cells $\left({ }^{156 / 164}, 95.1 \%\right)$, the load direction-dependent discharge variation was sufficiently broad and continuous as to show a good fit to a sinusoid (Table 3; Figs. 6; 7, $A, B$ ). It is interesting to note that unlike the case for movement direction, ${ }^{41 / 84}(48.8 \%)$ of the cells that failed the Rayleigh test for loads nevertheless showed a good fit to a sinusoid for load direction. In other words, $197 / 248$ $(79.4 \%)$ of the cells with significant $F$ tests for load direction during CHT showed broadly tuned, continuously graded changes in tonic rate. This is comparable to the proportion of cells showing approximately sinusoidal variations with movement direction (Table 2). However, for only $156 / 197$ (79.2\%) of these was the load direction-dependent variation of sufficient amplitude to 


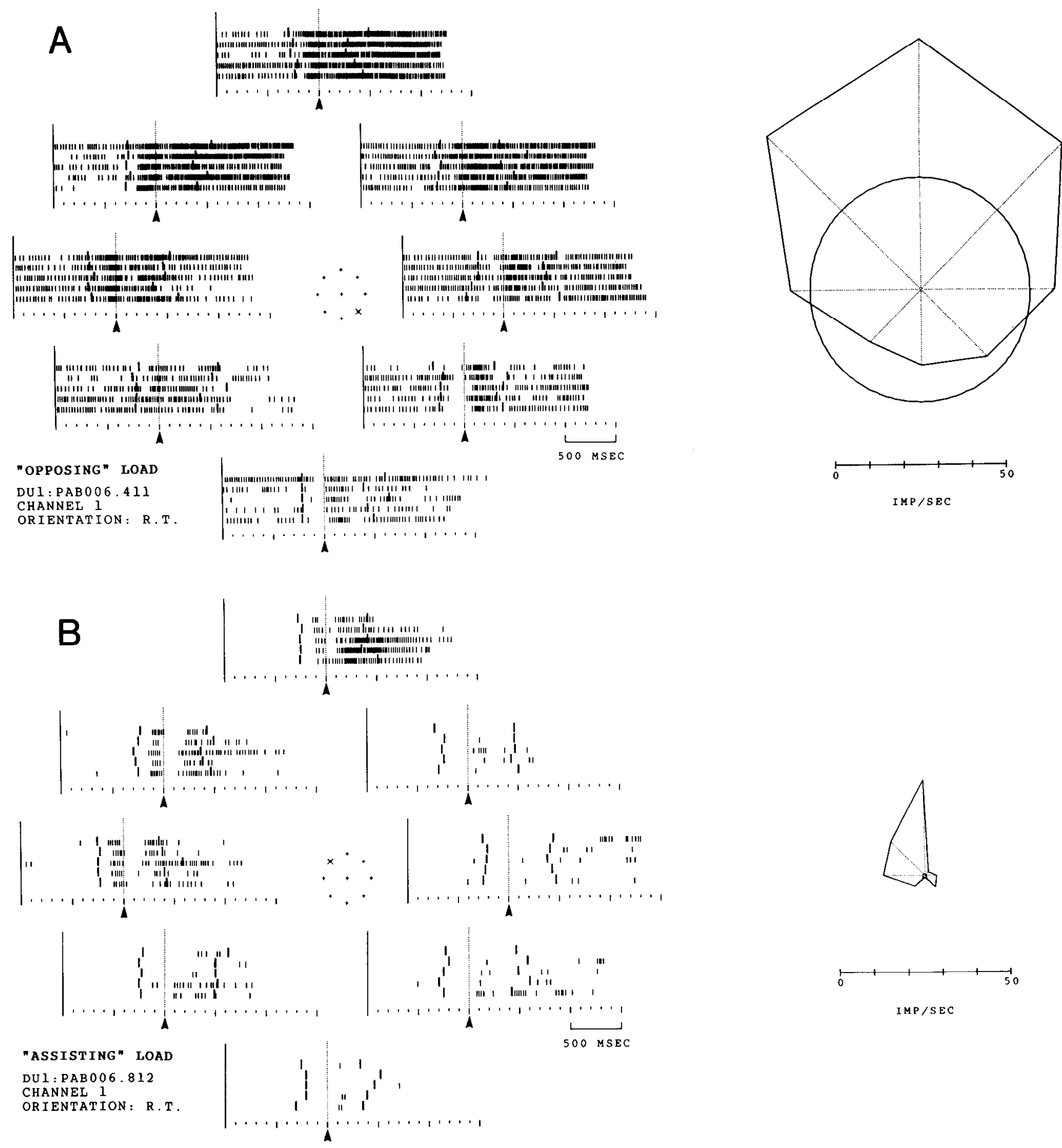

Figure 5. Effect of inertial loads at $315^{\circ}(A)$ and $135^{\circ}(B)$ on the discharge of the cell in Figure 4 .

represent a significant unimodal deviation from a uniform distribution. This suggests that load direction tended to produce smaller changes in cell activity during CHT than did movement direction in subsequent epochs of the trial.

Very similar results were observed for all subsequent behavioral epochs in the trial (Table 3). The analysis presented in Table 3 for RT, MT, THT, and RT + MT is based on the load direction-related variation of the grand mean of cell discharge measured across all 8 directions of movement in each load block. When a comparable analysis is done for each individual direction of movement, essentially the same results were obtained (data not shown).

The results of this experiment are summarized schematically in Figure 8, which illustrates the mean discharge of our total sample of cells. This figure is a 3-dimensional visual representation of the ANOVA structure of this task, including 8 directions of movement relative to the preferred direction of each cell plotted along one horizontal dimension and 8 load directions relative to the load axis plotted along the other horizontal dimension. The isolated curve plotted to the right along the 

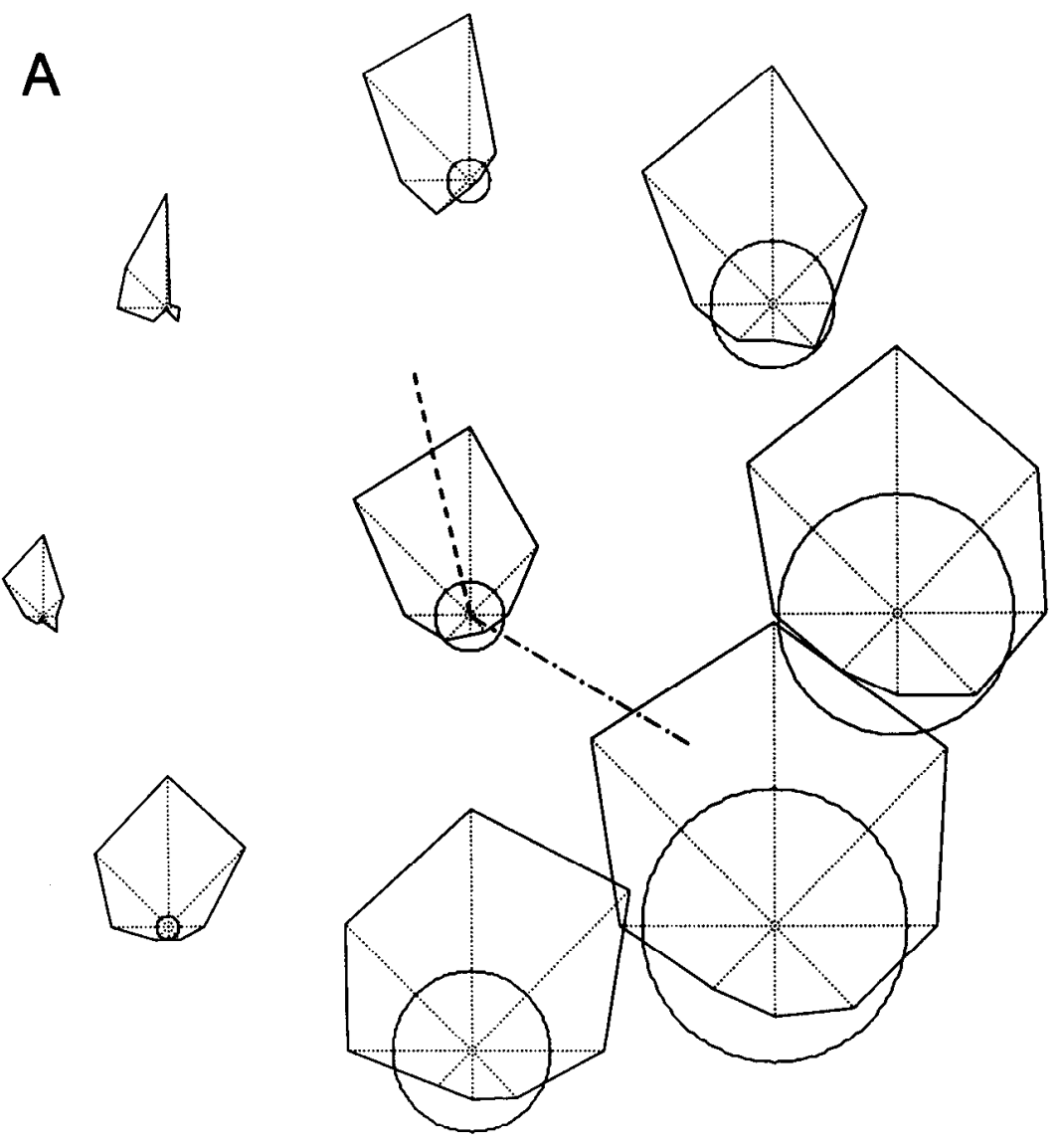

SAB 006

CHANNEL 1

$\mathrm{RT}+\mathrm{MT}+\mathrm{HT}$

$\longmapsto_{0}^{+1+1-1-1}$ IMP/SEC
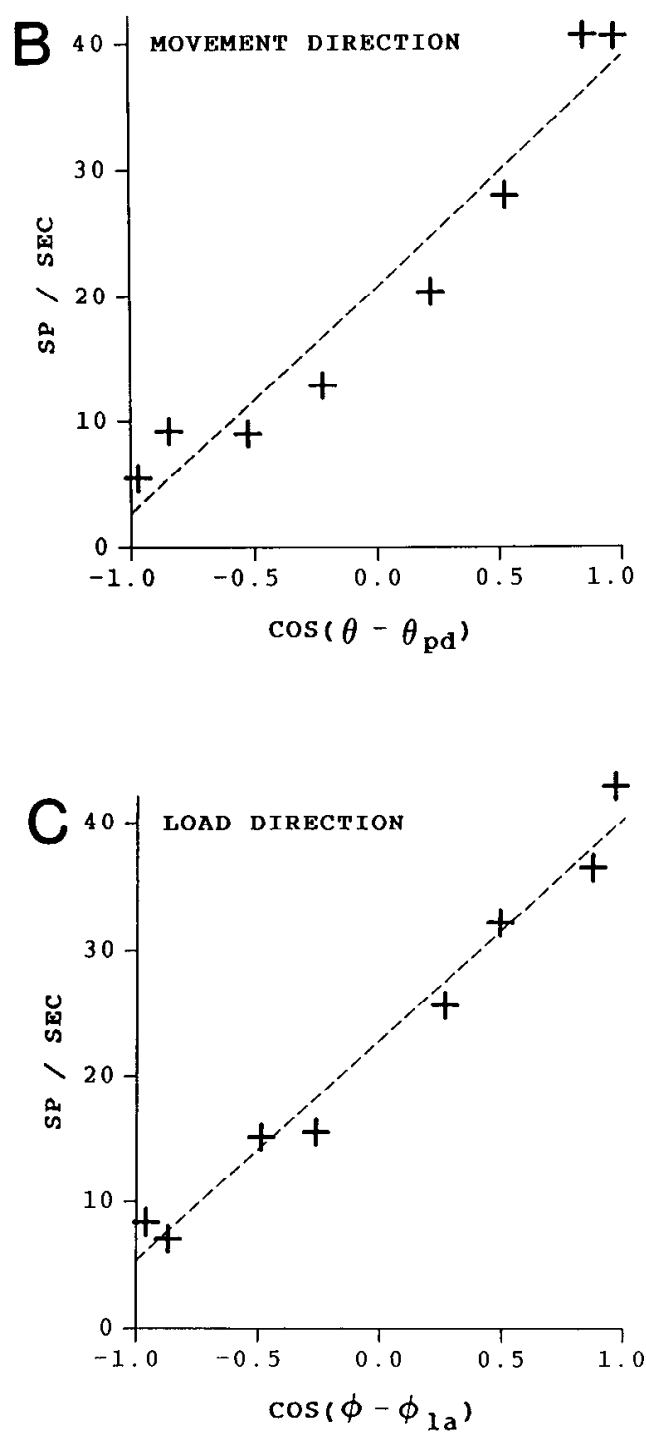

Figure 6. A, Polar-plot representation of the response of the cell in Figures 4 and 5 to all 8 directions of load. Loads produce large, continuously graded changes in cell discharge, in particular in tonic rate. This load direction-dependent variation shows an excellent fit $\left(R^{2}=0.98\right)$ to a sinusoidal curve of the form $y=22.97+17.48 \cos \left(\phi-\phi_{\mathrm{la}}\right)$, where $\phi_{\mathrm{la}}$ is the cell's load axis, $330^{\circ}$. Dashed line, preferred movement direction in control block; dot-dashed line, load axis. $B$, Variation of the mean cell discharge for different directions of movement relative to the preferred direction, in the control block. Dashed line, best-fit movement-direction function $y=20.80+18.15 \cos \left(\theta-\theta_{\mathrm{pu}}\right)$. C, Variation of the grand mean of cell activity averaged across all 8 directions of movement in each load block (i.e., mean of the 8 axes of each polar plot), as a function of the difference between load direction and the cell's load axis. Dashed line, best-fit load-direction function $y=22.97+17.48 \cos \left(\phi-\phi_{\mathrm{la}}\right)$.

movement-direction dimension is the variation of mean cell discharge for different directions of movement during the control block, centered on the preferred direction of each cell. This control movement-related curve represents the activity of the motor cortex population when the monkey moves the limb and pendulum without any external loads. This curve shows an excellent fit to a sinusoid (Table 4A). The horizontal dashed line represents the mean tonic rate $(12.42 \mathrm{imp} / \mathrm{sec})$ of the sample population during $\mathrm{CHT}$ in the control block. The isolated curve to the left in the figure represents the variation of the mean tonic discharge of the sample population recorded during CHT with different directions of load, relative to the load axis of each cell. This CHT load-related curve represents the tonic activity associated with load compensation while holding the arm over the central LED. This curve also shows an excellent fit to a sinusoidal function (Table 4B). It is not symmetric about the
Table 3. Tests of the load direction-dependent discharge variation of shoulder movement-related cells in a two-dimensional reaching task

\begin{tabular}{lccccc} 
Test & CHT & RT & MT & THT & RT + MT \\
\hline$F$ test & & & & & \\
sig $(p<0.05)$ & 248 & 243 & 250 & 250 & 254 \\
non-sig & 14 & 19 & 12 & 12 & 8 \\
\% & 94.7 & 92.7 & 95.4 & 95.4 & 96.9 \\
Rayleigh & & & & & \\
$\quad$ sig $(p<0.05)$ & 164 & 158 & 163 & 163 & 160 \\
non-sig & 84 & 85 & 87 & 87 & 94 \\
\% & 66.1 & 65.0 & 65.2 & 65.2 & 63.0 \\
Sinusoid & & & & & \\
sig $\left(R^{2}>0.7\right)$ & 156 & 148 & 158 & 158 & 158 \\
non-sig & 8 & 10 & 5 & 5 & 2 \\
\% & 95.1 & 93.7 & 96.9 & 96.9 & 98.8 \\
& & & & &
\end{tabular}



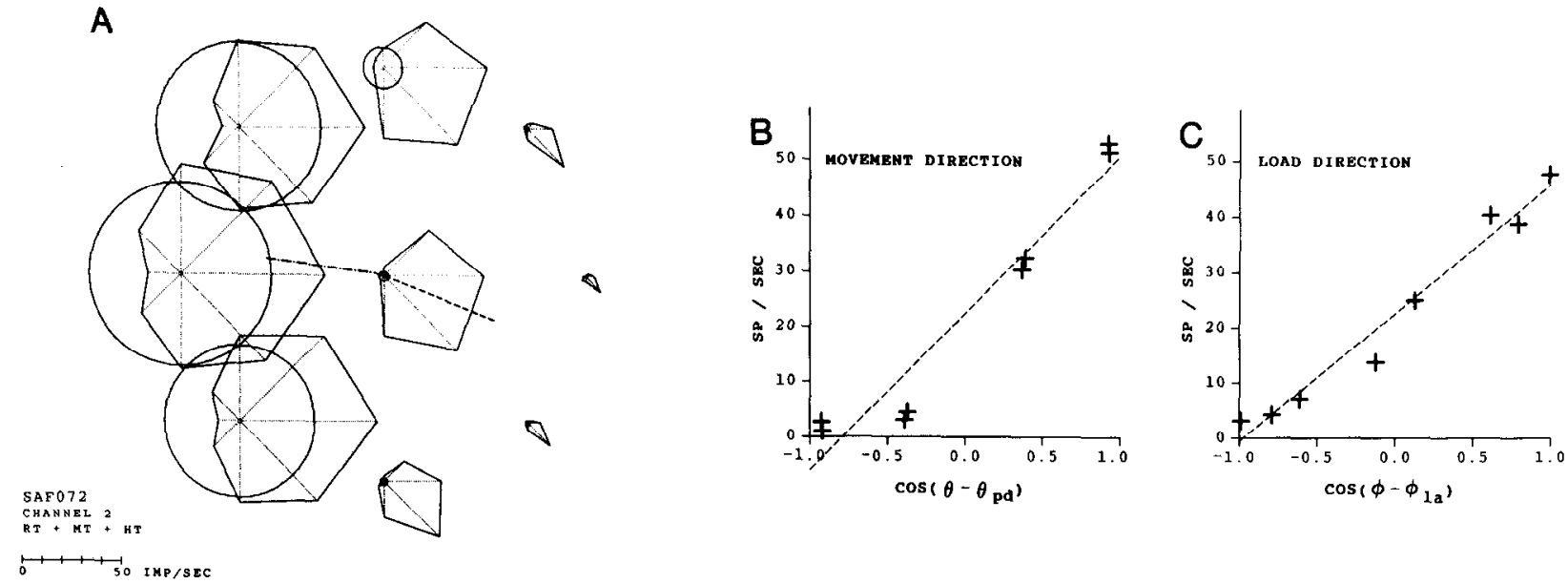

D
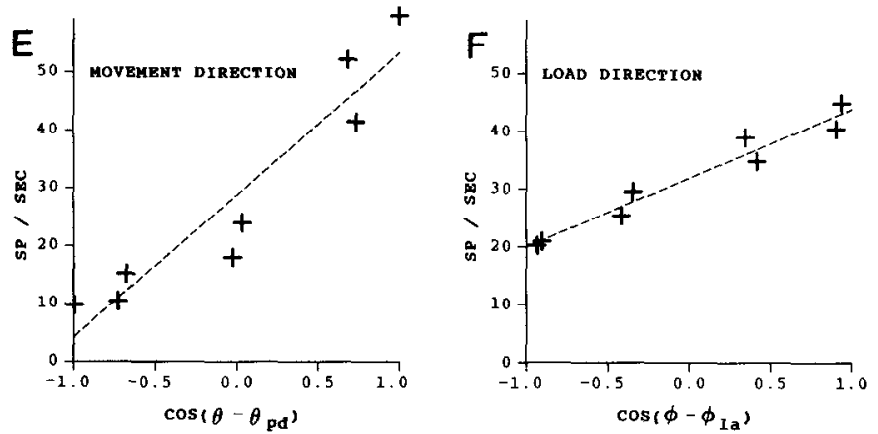

SAF0E2

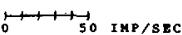
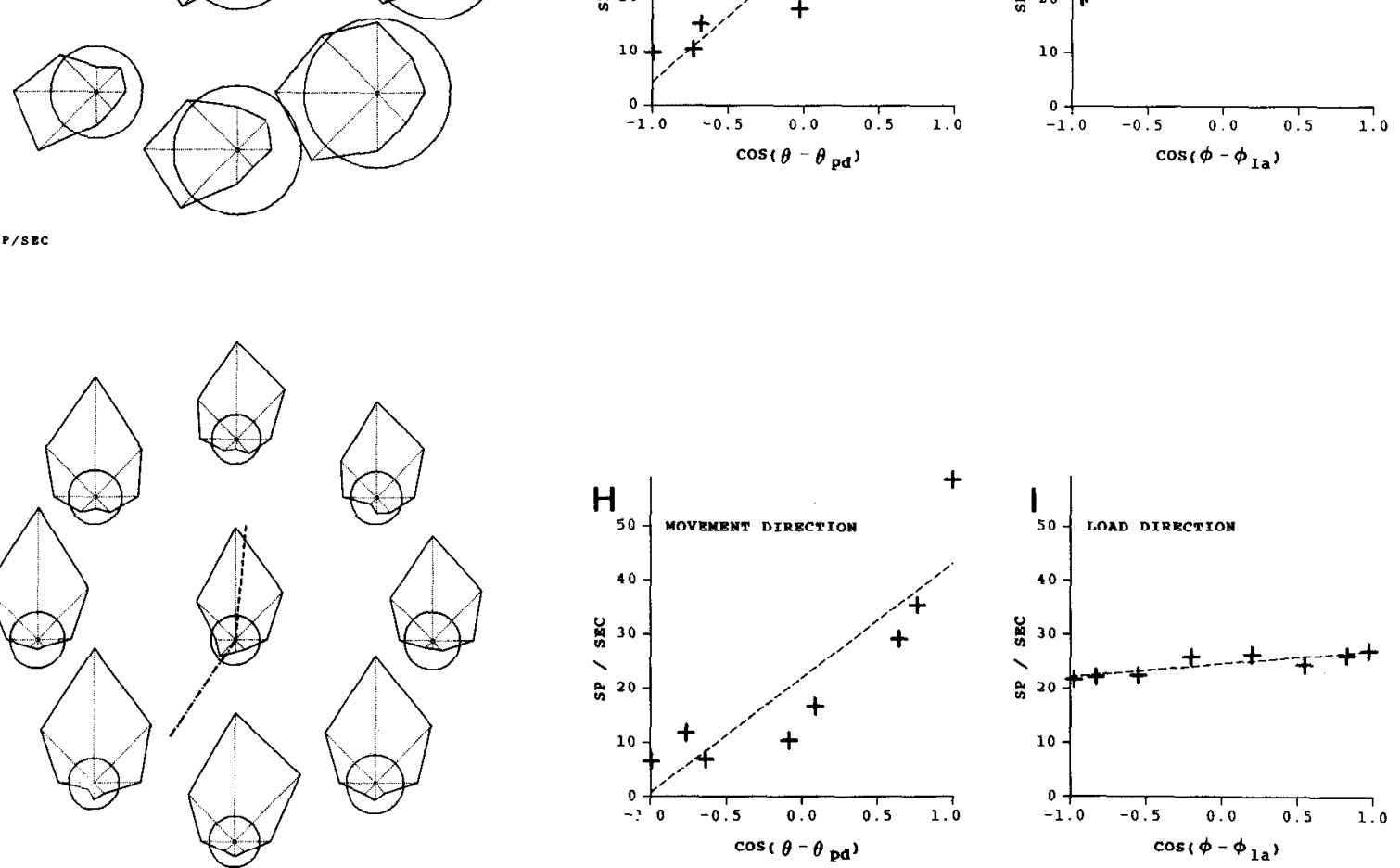

SAB003

G
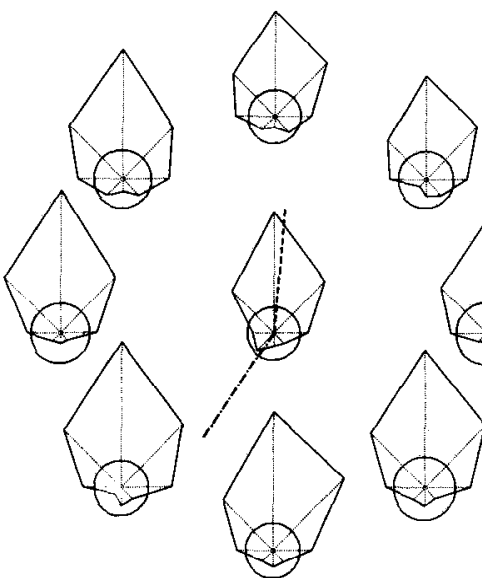

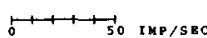

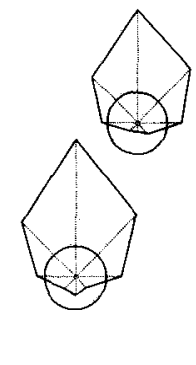

Figure 7. Responses of 3 shoulder joint-related area 4 cells in the task to illustrate the range of load direction-dependent activity changes seen in the sample population. Display format the same as in Figure 6. $A-C$, Cell whose best-fit movement-direction function was $y=22.43+28.55 \cos (\theta$ $\left.-\theta_{\mathrm{pd}}\right)\left(R^{2}=0.94\right)$ and whose best-fit load direction function was $y=22.64+23.32 \cos \left(\phi-\phi_{1 \mathrm{a}}\right)\left(R^{2}=0.97\right)$. $D-F$, Cell whose best-fit movementdirection function was $y=28.96+24.60 \cos \left(\theta-\theta_{\mathrm{pd}}\right)\left(R^{2}=0.89\right)$ and whose best-fit load direction function was $y=32.01+11.96 \cos \left(\phi-\phi_{12}\right)$ $\left(R^{2}=0.95\right) . G-I$, Cell whose best-fit movement-direction function was $y=22.00+21.18 \cos \left(\theta-\theta_{\mathrm{pd}}\right)\left(R^{2}=0.78\right)$ and whose best-fit load direction function was $y=24.59+2.43 \cos \left(\phi-\phi_{\mathrm{la}}\right)\left(R^{2}=0.75\right)$. 


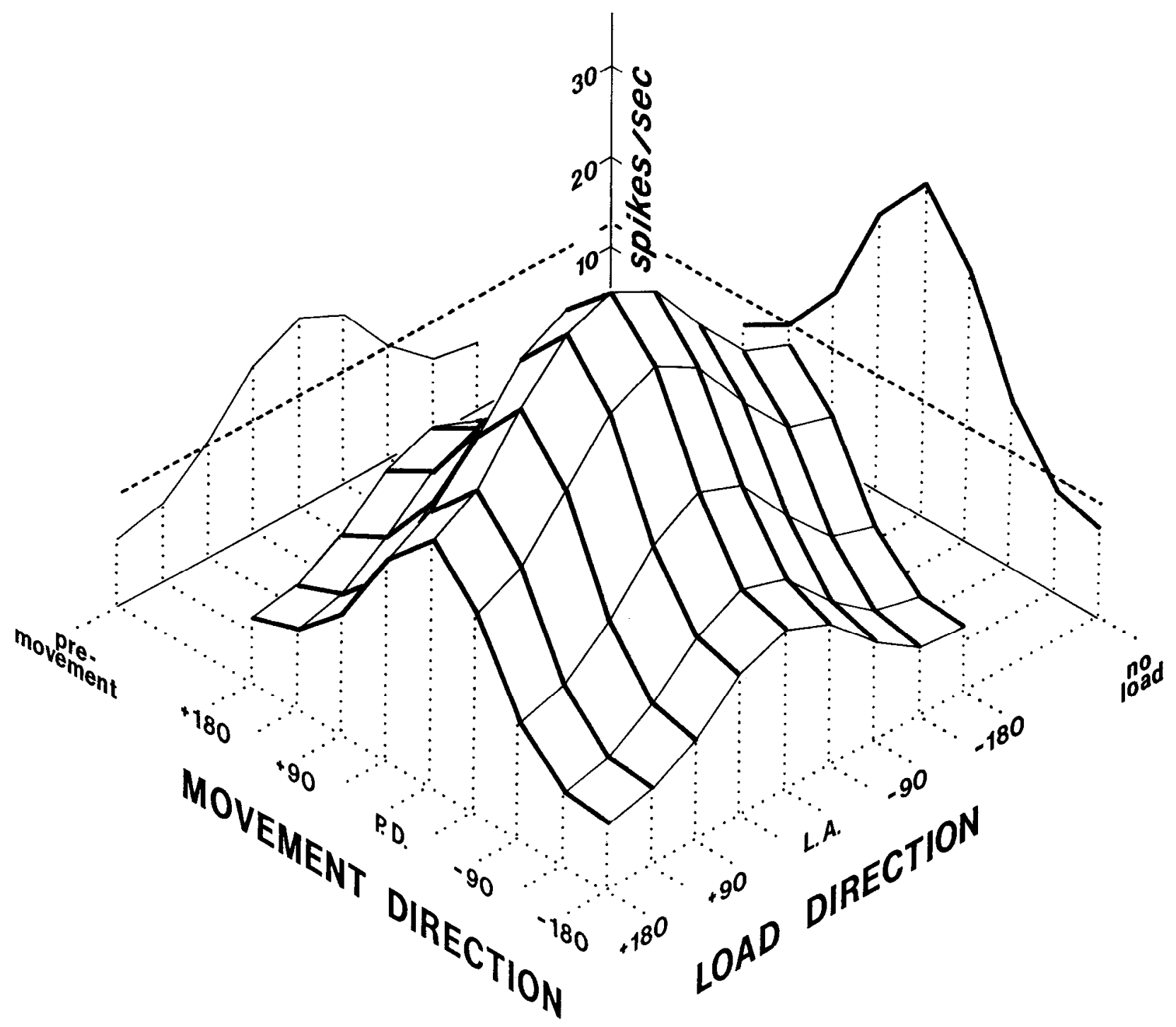

Figure 8. Schematic representation of the mean activity of the sample of 262 motor cortex cells in the task for all combinations of movement direction and load direction (see text for explanation of format). The vertical axis represents cell discharge rate (imp/sec). $P D, \mathrm{preferred}$ movement direction of each cell; $L A$, load axis of each cell.

control CHT tonic rate, increasing from $12.42 \mathrm{imp} / \mathrm{sec}$ to 20.83 $\mathrm{imp} / \mathrm{sec}$ at the load axis, but decreasing only to $7.42 \mathrm{imp} / \mathrm{sec}$ for assisting loads opposite to the load axis.

The curvilinear plane represents the mean activity of the population for all combinations of movement and load directions recorded from the appearance of the target LED to the end of the movement (RT + MT), centered on the preferred direction and load axis of each cell. Each of the curves making up this movement $\times$ load response plane shows an excellent fit to a sinusoidal function (Table 4). Therefore, both experimentally controlled spatial parameters, direction of movement and of load, produce qualitatively similar continuously graded changes in cell discharge in the motor cortex, when considering the behavior of individual cells (Table 3) and that of the summed population activity (Table 4 ).

\section{Vector representation of population activity}

Figure 9 illustrates the distribution of directions of the load axes of the cell sample relative to the preferred direction of each cell, which has been arbitrarily rotated to the left in the figure. Therc is a strong skew in the distribution such that the load axis tended to be oriented in the direction opposite to the preferred direction, as is evident from the single-cell examples in Figures 6 and 7 . There is also a considerable range in the distribution, including a few cells that counterintuitively showed increased activity with assisting loads near their preferred direction. These cells were exceptional, however, and had other distinguishing properties, which will be described elsewhere.

We used a vector notation to represent the activity of single cells during movement, in the control block (Fig. 10A). The activity of each cell was represented by a vector oriented along the axis of its preferred direction. The length of the vector was determined by the change in discharge of the cell for each direction of movement, relative to the tonic rate during CHT. This calculation was somewhat different to that used in a previous study (Georgopoulos et al., 1983, 1984b). If the cell increased its discharge for a given movement direction, the vector was pointed in the same direction as the preferred direction. If 

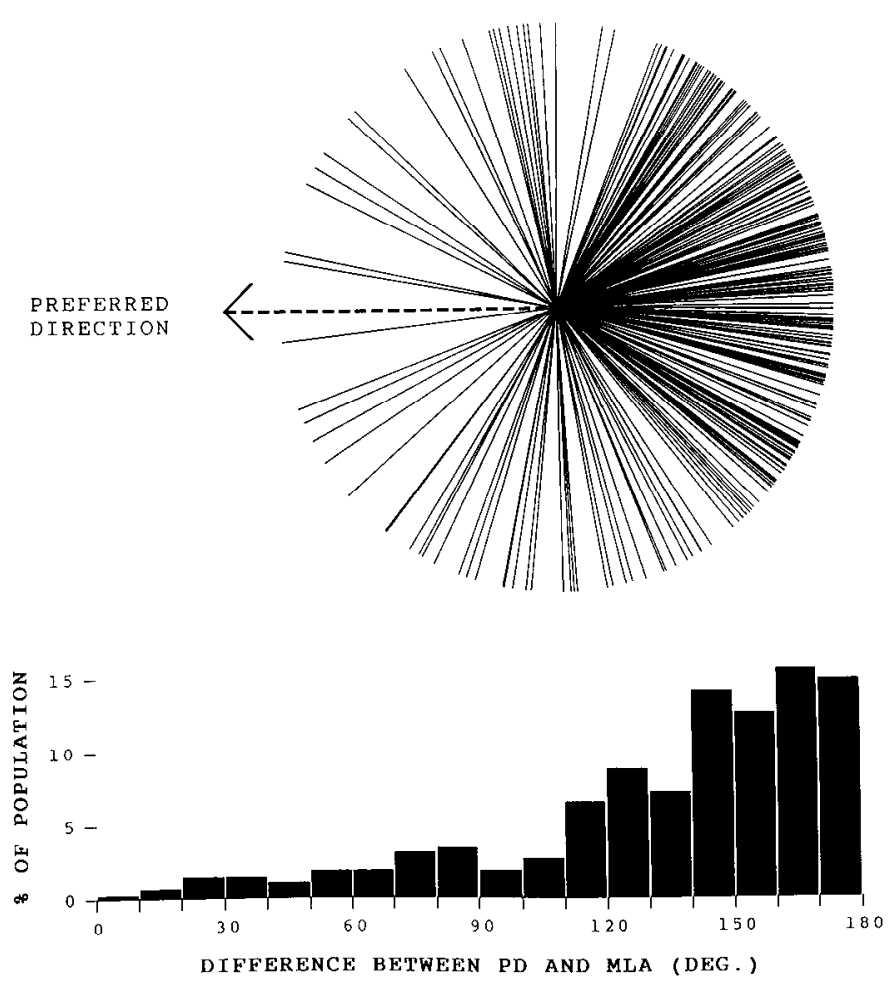

Figure 9. Distribution of the orientation of the load axis of single cells relative to their preferred movement direction, illustrated individually (top) and as a frequency histogram (bottom). To produce the top half of the figure, the preferred movement direction of each cell was rotated to the left (heavy dashed arrow) and the direction of the load axis relative to that arrow was plotted as a solid line. $P D$, preferred direction; $M L A$, load axis.

the cell decreased its discharge for a direction of movement, the vector was pointed in the direction opposite to its preferred direction. This analysis produces 8 vector clusters, each representing the movement-related activity of the sample population during one direction of movement (Fig. 10A). The position of each vector cluster corresponds to the direction of movement away from the center. The pattern of activity shifts with the direction of movement, and the vector sum of this pattern of activity is a vector (Fig. 10A, heavy arrows) that corresponds well to the direction of movement.

We used a similar notation to determine whether the change in activity caused by each load represents a signal of a direction appropriate to compensate for the loads (Fig. 10B). As before, the activity of each cell was represented by a vector oriented along the axis of its preferred direction measured in the control block. However, the length of the vector was determined by the change in discharge caused by a load, relative to the activity in the control block. The vector was pointed in the direction of the preferred direction or opposite to it, depending on whether the load caused an increase or reduction in activity. Each vector cluster represents the pattern of change in discharge of the sample population caused by one direction of load, and the position of the vector cluster corresponds to the direction in which the load pulls the manipulandum away from the center of the target panel (Fig. 10B). As was the case for movement, there was a wide range in the behavior of cells during load compensation. However, the vector clusters all tend to orient inward, and their overall pattern shifts with load direction, so that the vector sum of each cluster tends to point toward the center. Thus, the pattern

\begin{tabular}{|c|c|c|c|}
\hline $\begin{array}{l}\text { Direction } \\
\text { of load }\end{array}$ & $b_{0}$ & $c_{1}$ & $\begin{array}{l}\text { Coefficient } \\
\text { of deter- } \\
\text { mination }\end{array}$ \\
\hline \multicolumn{4}{|c|}{$\begin{array}{l}\text { A. Fit of variation of cell discharge across all directions of movement } \\
\text { (Fig. } 8 \text {, thick curves), for each direction of load, to a sinusoidal } \\
\text { function of the form } y=b_{0}+c_{1} \cos \left(\theta-\theta_{\mathrm{pd}}\right)^{a}\end{array}$} \\
\hline$-180^{\circ}$ & 15.24 & 9.24 & 0.956 \\
\hline$-135^{\circ}$ & 17.12 & 10.84 & 0.958 \\
\hline$-90^{\circ}$ & 21.84 & 12.65 & 0.967 \\
\hline$-45^{\circ}$ & 27.19 & 13.34 & 0.979 \\
\hline LA & 29.52 & 13.37 & 0.986 \\
\hline$+45^{\circ}$ & 27.16 & 12.88 & 0.986 \\
\hline$+90^{\circ}$ & 21.39 & 11.86 & 0.979 \\
\hline$+315^{\circ}$ & 16.62 & 10.45 & 0.962 \\
\hline No load & 20.99 & 13.31 & 0.968 \\
\hline $\begin{array}{l}\text { Direction } \\
\text { of movement }\end{array}$ & $b_{0}$ & $c_{1}$ & $\begin{array}{l}\text { Coefficient } \\
\text { of deter- } \\
\text { mination }\end{array}$ \\
\hline \multicolumn{4}{|c|}{$\begin{array}{l}B \text {. Fit of variation of cell discharge across all directions of load (Fig. } 8 \text {, } \\
\text { thin curves), for each direction of movement, to a sinusoidal function } \\
\text { of the form } y=b_{0}+c_{1} \cos \left(\phi-\phi_{1 \mathrm{a}}\right)^{a}\end{array}$} \\
\hline$-180^{\circ}$ & 11.92 & 5.34 & 0.983 \\
\hline$-135^{\circ}$ & 14.15 & 5.81 & 0.991 \\
\hline$-90^{\circ}$ & 20.43 & 7.41 & 0.997 \\
\hline$-45^{\circ}$ & 30.56 & 8.53 & 0.998 \\
\hline PD & 35.93 & 8.58 & 0.999 \\
\hline$+45^{\circ}$ & 30.17 & 8.61 & 0.999 \\
\hline$+90^{\circ}$ & 19.69 & 7.62 & 0.993 \\
\hline$+135^{\circ}$ & 13.25 & 5.91 & 0.989 \\
\hline Center hold & 13.78 & 7.04 & 0.990 \\
\hline
\end{tabular}

${ }^{a}$ See Materials and Methods for details.

of change of activity in the motor cortex caused by a load is appropriate to compensate for the external load.

Note, however, that the orientation of the vector sum is not exactly opposite to the load direction in all cases, and so does not always point directly toward the center. Furthermore, the length of the vector sum varies with the direction of load, being substantially longer for those that pull the limb from side to side and shorter for those loads that pull the limb toward or away from the body.

\section{Additivity of movement and load effects}

As previously noted, the most striking change in activity caused by loads was in the overall tonic level of cell discharge (Figs. 5-8), and the load-dependent changes in discharge were observed across all epochs with fairly constant frequency (Table 3). One measure of the strength of the load effect is the loaddirection range, the difference in mean discharge between directions of load producing the strongest and weakest discharge in each epoch. The load-direction range calculated in different epochs tended to remain constant throughout the trial (Fig. 11). Table 5 presents a similar analysis for the total population and for the 4 monkeys from which large data samples were collected. All correlations were highly significant $(p<0.01,2$-tailed $t$ test). The correlations were higher in 3 of the 4 individual monkeys 


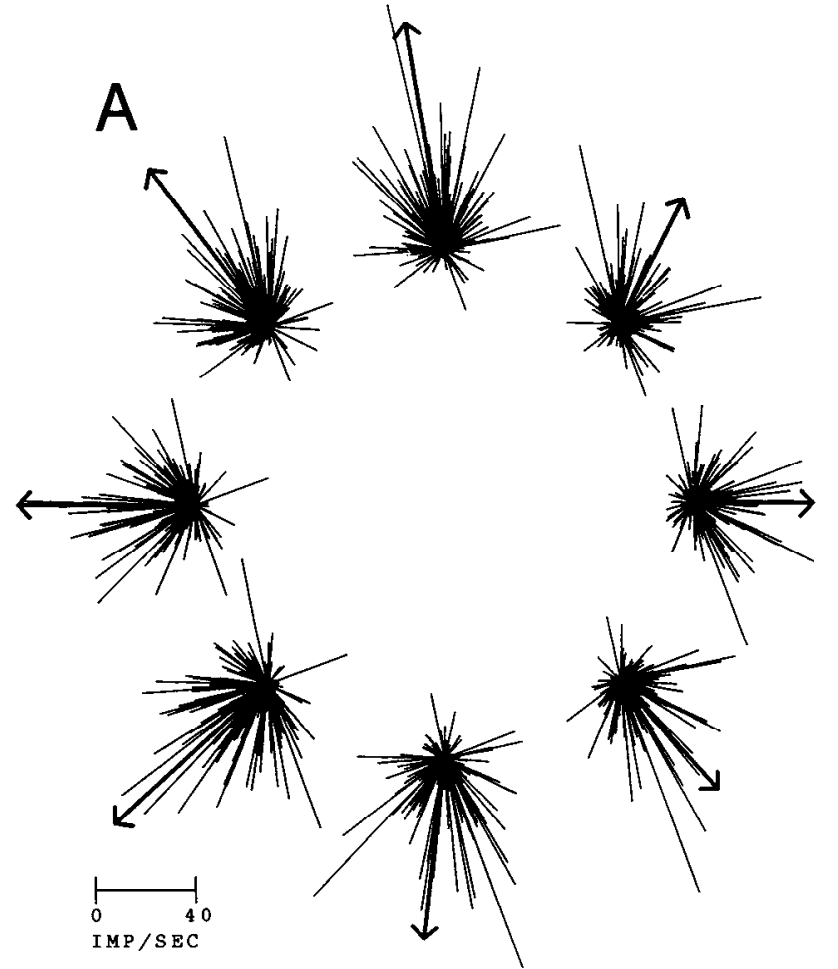

NO-LOND MOVEMENT RESPONSE: RT+MT

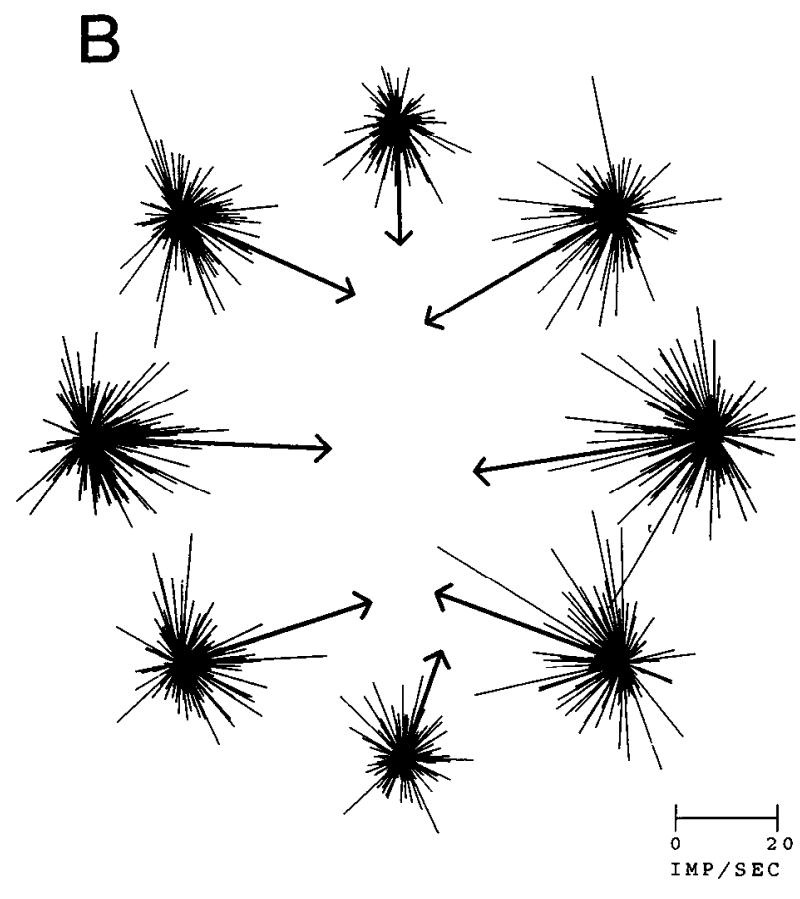

LOAD-COMPENSATION RESPONSE : RT+MT

Figure 10. Vector representation of the behavior of the sample population during different directions of movement with no loads $(A)$ and during compensation for different directions of load $(B)$. The position of each cluster corresponds to the direction of movement away from the central starting position $(A)$ or to the direction in which the load pulls the pendulum away from the center of the target panel $(B)$. The heavy arrows are the vector sums of each vector cluster.

than for the pooled data sample. In all cases, the slope of the relation was near 1.0. It is interesting to note that the correlation was lower for the MT epoch when the limb was moving, than for the RT and THT epochs, when the limb was stationary.

These observations suggest that the inertial loads produced approximately equal changes in cell discharge throughout all epochs of the trial, starting with the tonic rate changes in CHT. However, the lower correlations during MT indicate that the load-related tonic activity changes observed during CHT were a poorer predictor of the load-related activity changes during MT than at any other time in the trial. Examples of different types of effects are seen in Figure 12, which illustrates the discharge of 4 different cells for movements at their preferred direction, when no load was applied to the handle (center histogram) for a load at its load axis (left) and for a load opposite the load axis (right).

In Figure $12 A$ is a cell whose tonic rate ranged between 1 and $33 \mathrm{imp} / \mathrm{sec}$ under different load conditions, while its movementrelated response (the change in discharge compared with the tonic rate during $\mathrm{CHT}$ ) remained nearly constant under all load conditions. Consequently, its load-direction range remained nearly constant across all epochs. Its activity appeared to be the simple summation of a movement-related discharge and a loadrelated tonic rate, without any interaction between movement and load-compensation processes.

Figure $12 B$ illustrates a cell that showed a linear summation of the load-dependent tonic activity and movement-related response for opposing loads but a large reduction in movementrelated response for assisting loads. The load-direction range of this cell was greater during movement than during CHT.
Figure $12 C$ illustrates a neuron that exhibited a saturation effect. Its absolute discharge frequency during movement remained approximately constant under all load conditions, so that the movement-related response was reduced for loads near the load axis, where tonic rates were elevated, and increased for

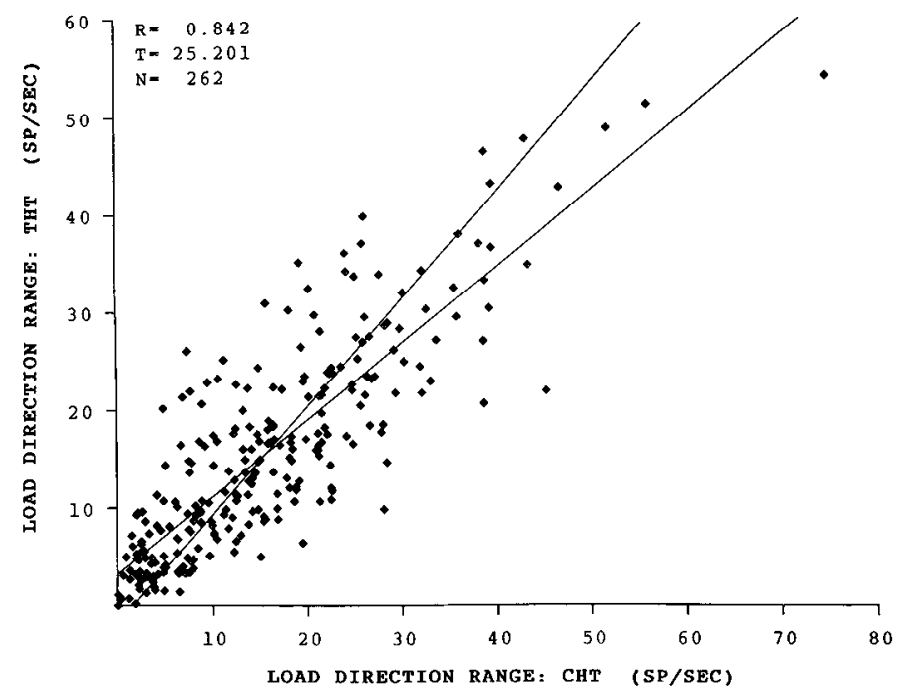

Figure 11. Correlation between the size of the load direction-dependent discharge variation (load-direction range; see text) for cells during the CHT and THT. The data cluster along the identity relation, indicating that the changes in discharge produced by the loads were of nearly uniform magnitude throughout the trial. 

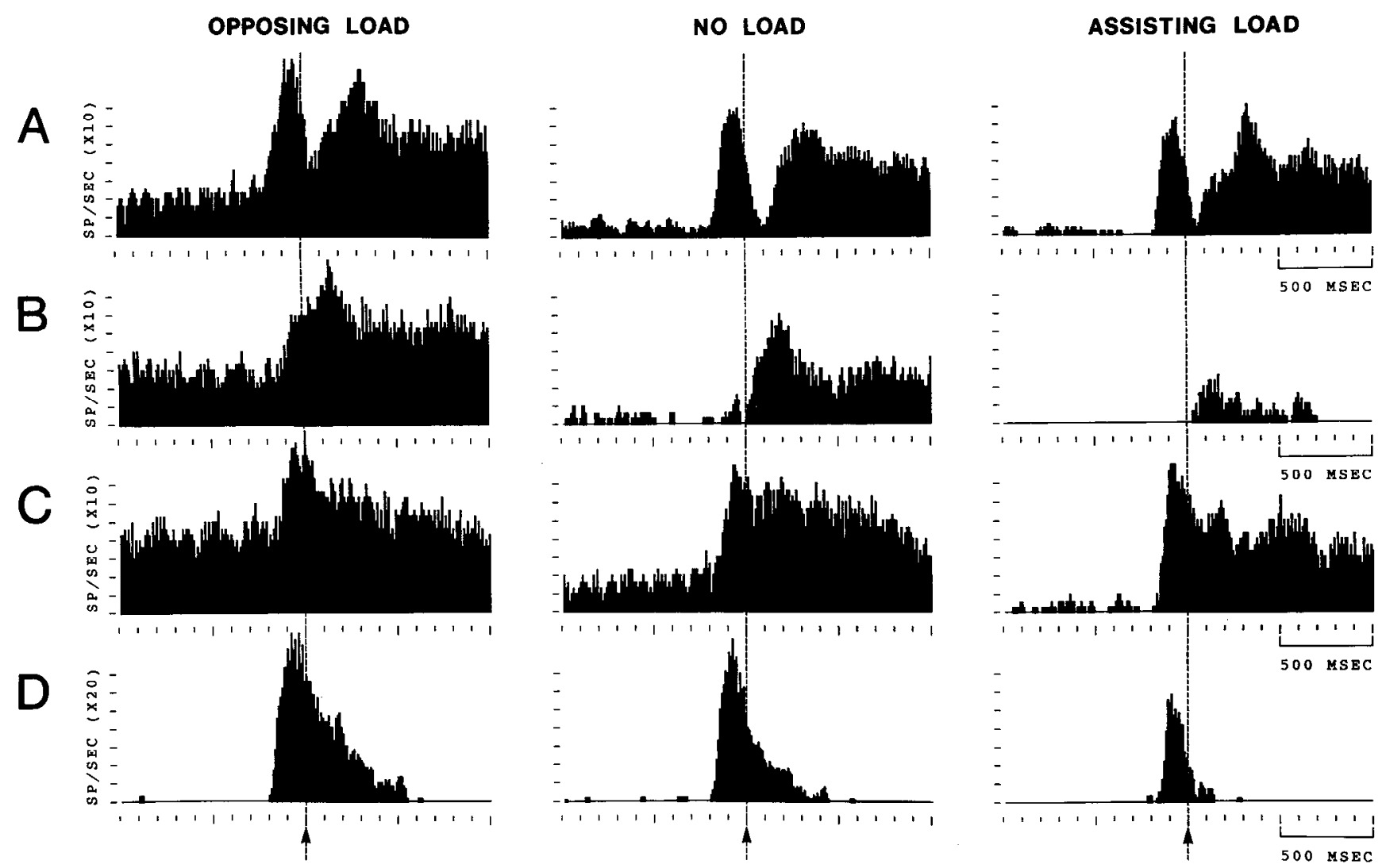

Figure 12. Discharge of 4 cells for movements at their preferred directions, under different load conditions. Data collected with opposing loads near the load axis are at left; data collected during control blocks, center; and cell responses to assisting loads opposite to the load axis, right.

assisting loads. As a result, its load-direction range was much smaller during movement than during CHT.

Somcwhat less commonly, cells showed large changes in their movement-related response but relatively little variation in tonic activity under different load conditions (Fig. 12D).

Many cells showed combinations of these various effects. For instance, the cell in Figure $7 A$ showed evidence of saturation of its movement-related response for loads near the load axis and decreases in movement-related response for loads opposite to the load axis compared with that seen in the control block.

To measure these interaction patterns more quantitatively, we calculated the movement-related response as the difference between the absolute mean discharge recorded during RT + MT for each movement direction, and the tonic rate observed during CHT. One can then compare this response for similar movement directions under different load conditions. Figure $13 \mathrm{~A}$ shows the distribution of the difference in the movement-

\begin{tabular}{|c|c|c|c|c|}
\hline & RT & $\mathrm{MT}$ & THT & $\mathrm{RT}+\mathrm{MT}$ \\
\hline Total sample & 0.882 & 0.706 & 0.842 & 0.802 \\
\hline Monkey 1 & 0.820 & 0.512 & 0.806 & 0.652 \\
\hline Monkey 2 & 0.891 & 0.825 & 0.933 & 0.903 \\
\hline Monkey 4 & 0.884 & 0.756 & 0.858 & 0.855 \\
\hline Monkey 5 & 0.948 & 0.862 & 0.918 & 0.838 \\
\hline
\end{tabular}

related response at the preferred direction of each cell between the control block and the load block nearest the cell's load axis. A positive difference signifies that the movement-related response was greater with the opposing load than in the control block, and a negative difference that it was less. Although a wide range of load-induced differences is evident, the distribution is normally distributed and centered near zero (mean $=-1.3 \mathrm{imp}$ / sec). This indicates that the mean movement-related response of the total population for movements at the preferred direction remains approximately constant under the opposing load condition. This relation holds for all other directions of movement for a load at the load axis (Fig. 13B). The control and load axis curves are virtually identical and parallel one another, with an offset approximately equal to the difference in mean tonic rate of the population during CHT in the 2 data blocks. As a result, the major effect of the opposing load on the population behavior appeared to be an increase in mean tonic activity, while the mean movement-related response varying about that elevated baseline remained nearly constant.

If this relation held for all other load directions, then the movement $\times$ load response plane of Figure 8 would be the simple summation of the control movement-related curve and the variation of the CHT load-related curve about the control $\mathrm{CHT}$ tonic rate. Alternatively, subtraction of the change in CHT tonic rate caused by each load from the movement-related curves under load should produce a series of curves identical to that for the control movement-related curve. The result of such a subtraction is seen in Figure 14. The movement-related curves near the center of the plane, for loads near each cell's load axis, 

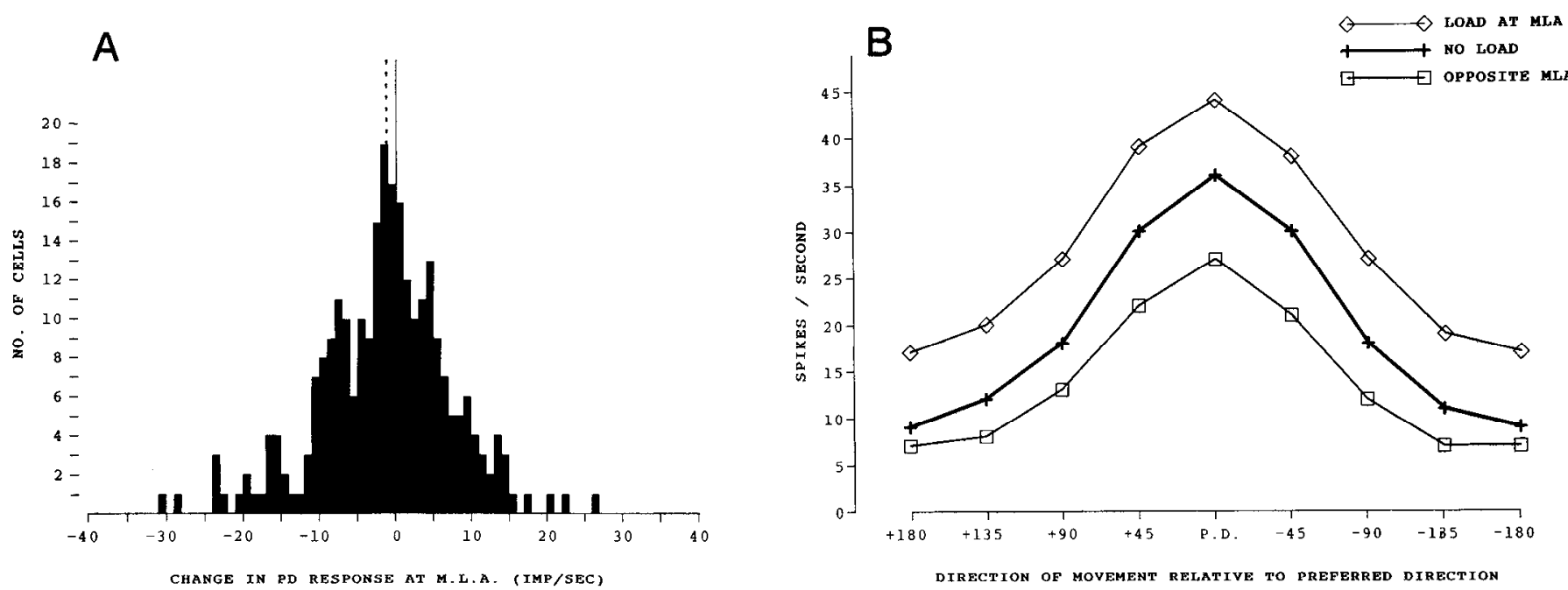

Figure 13. Effect of loads on activity during movement. $A$, The distribution of the difference in the movement-related response for movements at the preferred direction $(P D)$ between the control block and the data block nearest the load axis $(M L A)$. $B$, Mean absolute discharge rate of the population for all movement directions with no load (heavy curve), the load block nearest the load axis (diamonds), and the load opposite the load axis (squares). $P D$, preferred direction; $M L A$, load axis.

are virtually identical to that for the control curve (cf. Fig. 13B). Deviations from simple additivity appear for loads opposite to each cell's load axis. This appears to occur because the variation of the mean movement-related response of the population becomes smaller than expected compared with the control condition (Fig. 13B).

These findings can also be derived from Table $4 A$, where the half-wave amplitude $c_{1}$ of the best-fit sinusoid for the movement-related curves of Figure 8 is approximately equal to that of the control curve for loads near the load axis but less for assisting loads opposite to the load axis.

\section{Factors related to strength of load effect}

There was a broad range in the strength of the effect of load direction on cell discharge (Fig. 7). An important question relates to which properties of the neurons might determine whether a given cell makes a major contribution to the compensation for loads in this task.

As in many previous studies, we observed that the cells could be sorted into a small number of classes according to the temporal pattern of discharge during movement at their preferred direction. We distinguished 2 general cell types, phasic and tonic. Phasic cells showed little or no posture-related change in their tonic discharge rate over the different targets during THT, compared with that during $\mathrm{CHT}$. In contrast, tonic cells showed large posture-related changes in tonic rate between $\mathrm{CHT}$ and THT. These 2 types could be divided into 2 further classes (Fig. 15). Cells of the first class, phasic-RT cells (Fig. 15A, 24 cells), generated a strong phasic burst confined primarily to the RT epoch and were relatively inactive during the rest of the trial. The second class of neuron, phasic-MT, emitted a longer phasic burst whose maximum frequency occurred during the MT epoch and which continued until near the end of movement (Fig. 15B, 75 cells). Tonic cells (Fig. $15 C$, 57 cells) showed modulations in tonic rate often beginning at or after the onset of movement but modest or no phasic activity during RT or MT. Cells of the fourth class, phasic-tonic cells, generated a brisk initial burst of activity, again typically confined to the RT epoch, that was terminated by a brief decrease or complete cessation of activity and then followed by an increase in tonic activity that was sustained throughout the THT period (Fig. 15D, 73 cells). The temporal patterns of discharge of the sample population in reality formed a complex continuum. For instance, the phasic-RT and phasic-MT cells were arbitrarily distinguished by the duration of their discharge and the time of its peak intensity relative to the onset of movement, but they may, in fact, represent one functional class. Likewise, many phasic-MT cells showed modest tonic activity changes associated with different movement end points, while many tonic cells showed a modest phasic component peaking during MT (Fig. $15 \mathrm{C}$ ). Furthermore, the

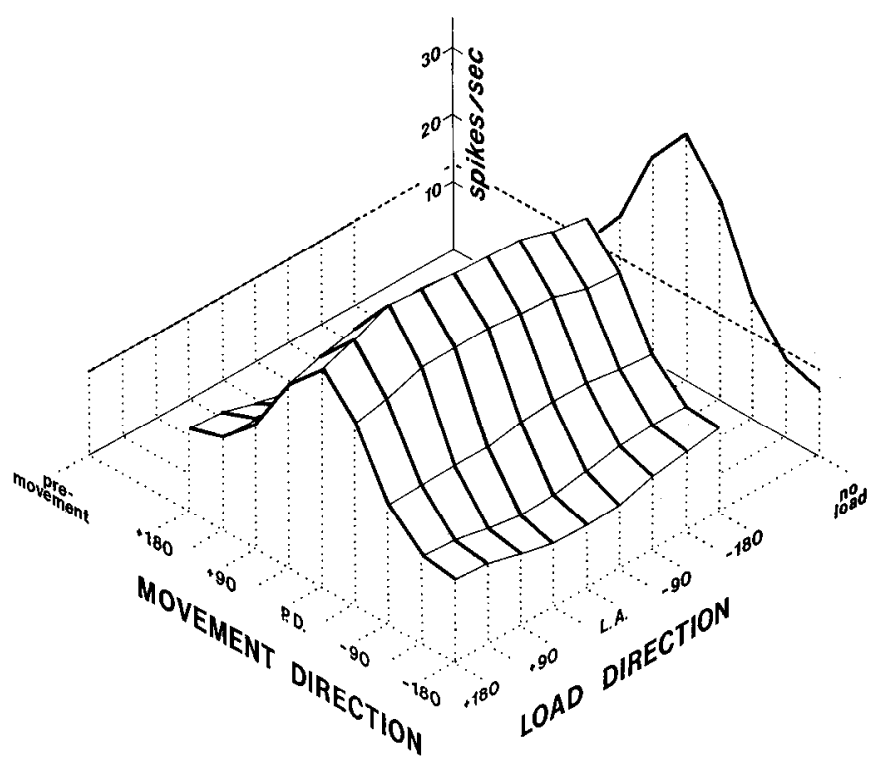

Figure 14. A test of the hypothesis that the behavior of the motor cortex sample population under any condition of movement and load direction can be predicted by the linear summation of the movementrelated discharge in the no-load condition, and the change in tonic discharge during CHT caused by loads. It was calculated by subtracting from the curvilinear plane of Figure 8, the difference between the CHT tonic rate under loads, and the control tonic rate. 

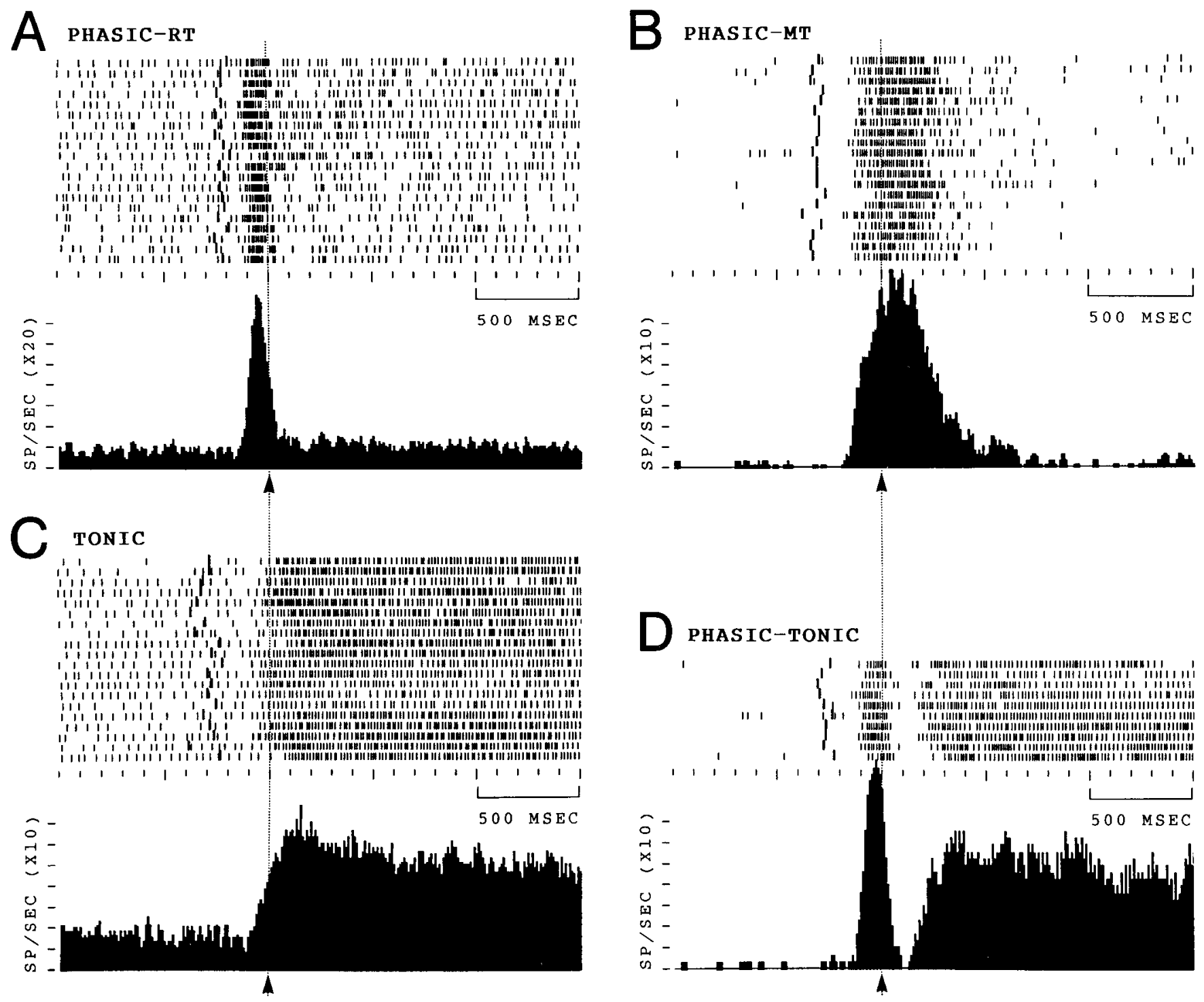

Figure 15. Examples of 4 different temporal patterns of activity seen in shoulder-related motor cortex cells during movements at their preferred direction. Vertical dotted line and arrows: onset of movement.

intensity of these various response components, and even the temporal activity pattern of single cells often varied with movement direction (cf. Fig. 4). Nevertheless, most of the cells could be assigned with confidence to 1 of these 4 arbitrary classes based on the predominent characteristics of their activity at the preferred movement direction.

We repeated the analysis of Figure 8 for each of these 4 cell classes for each of the epochs RT, MT, and THT (Fig. 16). Cells of the phasic-RT and phasic-MT classes showed relatively modest changes in both their tonic and movement-related activity under different directions of load, while cells of the tonic and phasic-tonic classes showed substantially greater load-dependent changes. The phasic-tonic cells showed the greatest load sensitivity overall. These differences among the cell classes were consistent across all epochs of the trial (Fig. 16). Note that the cells in Figures 4-6 and $7 A$ were phasic-tonic neurons, the cell in Fig. $7 B$ was tonic, and that in Fig. $7 C$ was a phasic-MT neuron.

The Rayleigh test indicated that $6 / 24$ phasic-RT cells, $30 / 75$ pha-
sic-MT cells, ${ }^{41 / 57}$ tonic cells, and $70 / 73$ phasic-tonic cells showed significant unimodal load-dependent activity changes during CHT. These differences among classes are highly significant $\left(\chi^{2}\right.$ test, $p<0.01)$. The phasic-tonic cells showed the greatest proportion of cells with large activity changes, which was significantly different even from the tonic group ( $\chi^{2}$ test, $\left.p<0.01\right)$. The differences in proportions among classes remained relatively constant during the RT, MT, and RT + MT epochs for all cell types except the phasic-RT cells. The latter cells exhibited a modest increase in the proportion of cells that showed significant Rayleigh results during RT ( $8 / 24)$ and MT (11/24).

Inspection of Figure 16 suggests that the sensitivity of each cell class to loads was best related to the degree of discharge variation of the control movement-related curve during THT, and not during either RT or MT. By analogy to the load-direction range, one can define the movement-direction range as the difference between the strongest and weakest discharge observed for different directions of movement in the control block. The correlation between the movement-direction and the load-di- 

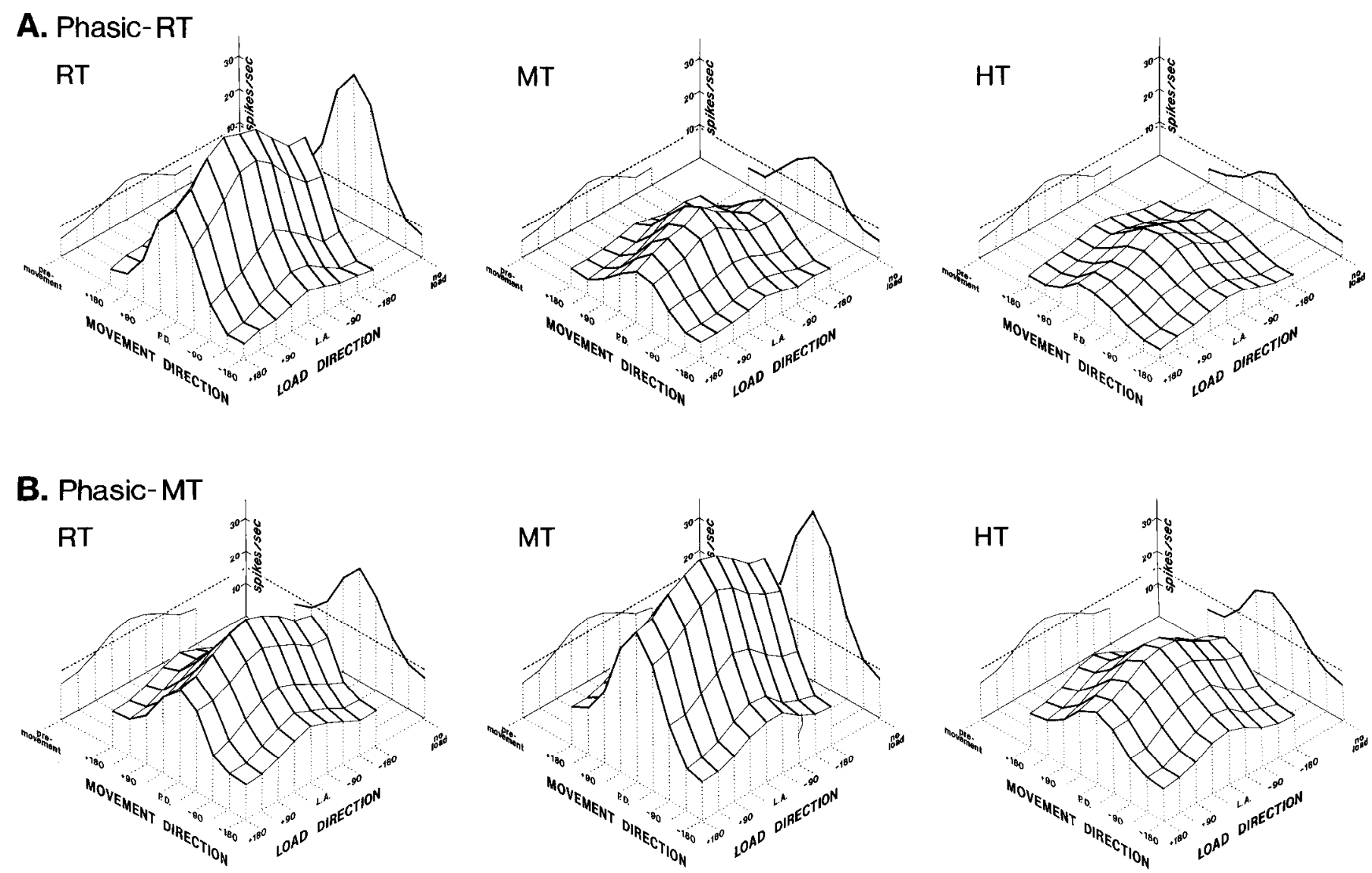

C. Tonic
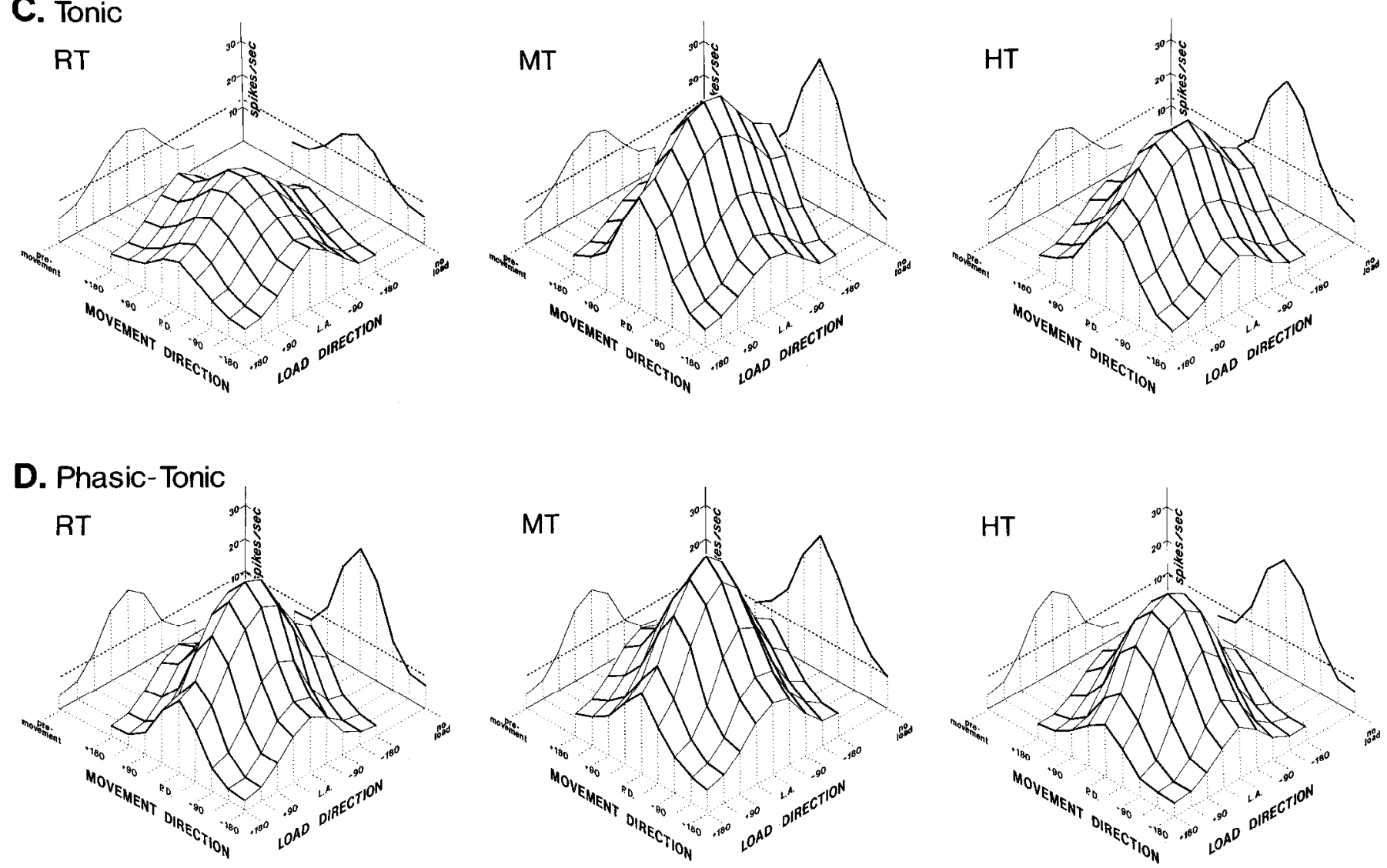

Figure 16. Comparison of the mean response of cells with different temporal patterns of activity. Same display format as Figure 7. While all 4 types show equal degrees of movement direction-related variation at one time or another during the trial, the 2 phasic groups are less affected by loads, on average. 

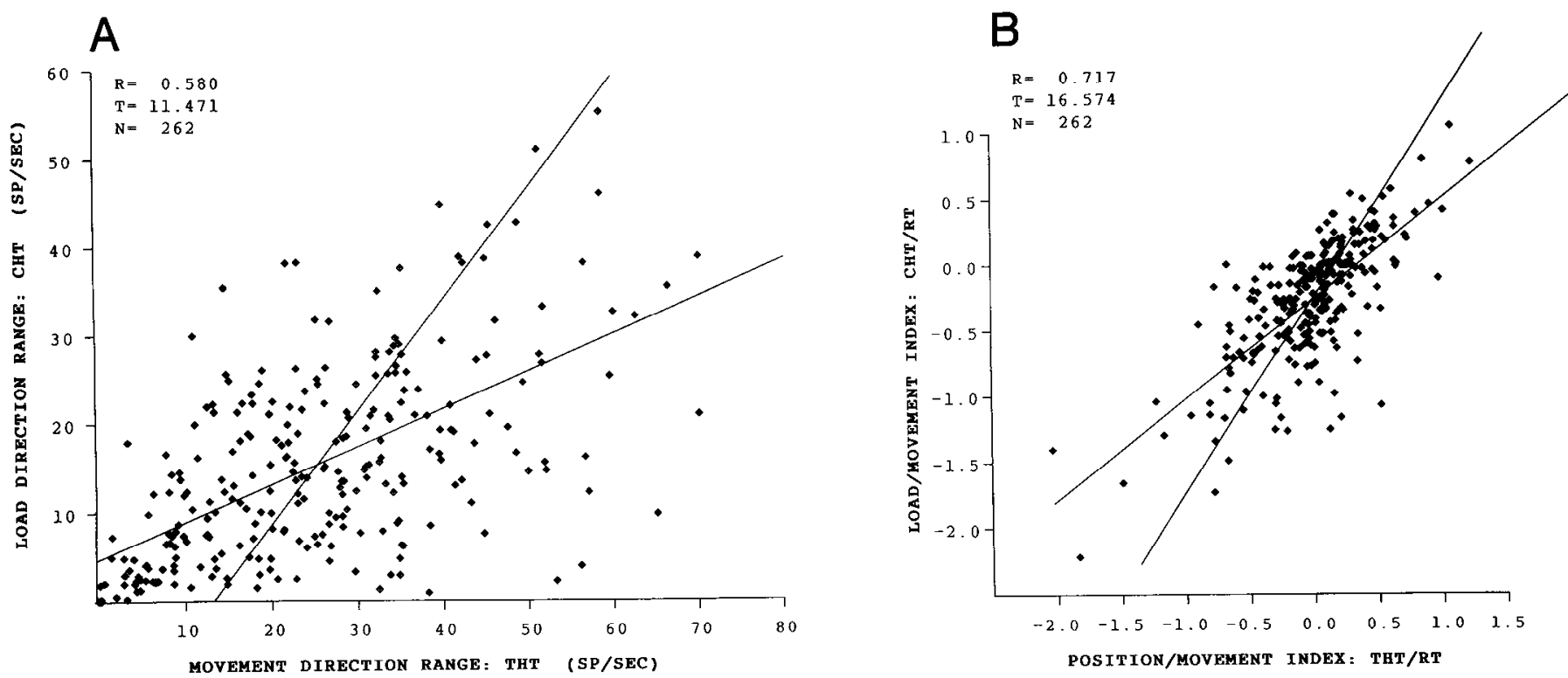

Figure 17. Correlations between movement direction-related and load direction-related discharge variations. $A$, Cells with large arm positionrelated activity changes tend to show large load direction-related changes in tonic discharge. $B$, Similar comparison, normalized for the movementdirection range observed during RT. Cells that are phasically activated in the task (small position/movement index) show weaker load-related effects than do cells that are more strongly related to postural maintenance.

rection ranges is weak for $\mathrm{RT}, \mathrm{MT}$, and $\mathrm{RT}+\mathrm{MT}$ but good for THT for both the total sample and for each monkey (Fig. $17 A$; Table $6 A$ ). While all of these correlations are statistically significant for the total sample, only that for the THT is significant for each individual monkey and is sufficiently large to account for a significant portion of the total variability of population behavior (coefficient of determination $=0.335$ for the total sample and $0.29-0.55$ for individuals). Thus, cells that show large variations in tonic rate related to different limb pustures tend to show greater changes in tonic rate while compensating for loads in different directions.

One factor that is confounded in this analysis is the difference in the overall frequency range of activity of different cells. A

Table 6. Correlations between movement direction-related and load direction-related discharge variations

$\begin{array}{llll}\text { RT } & \text { MT } & \text { THT } & \text { RT }+M T\end{array}$

4. Correlation between movement-direction range in different epochs and load-direction range measured during $\mathrm{CHT}$

$\begin{array}{llrrl}\text { Total sample } & 0.233^{b} & 0.160^{b} & 0.580^{b} & 0.196^{b} \\ \text { Monkey 1 } & 0.323^{b} & -0.011 & 0.537^{b} & 0.081 \\ \text { Monkey 2 } & 0.208 & 0.294 & 0.744^{b} & 0.270 \\ \text { Monkey 4 } & 0.183 & 0.142 & 0.578^{b} & 0.163 \\ \text { Monkey 5 } & 0.539^{b} & 0.251 & 0.643^{b} & 0.348^{a}\end{array}$

$B$. Correlation between the position/movement index and the load/ movement index (see text)

$\begin{array}{llll}\text { Total sample } & 0.717^{b} & 0.609^{b} & 0.637^{b} \\ \text { Monkey 1 } & 0.762^{b} & 0.651^{b} & 0.676^{b} \\ \text { Monkey 2 } & 0.841^{b} & 0.702^{b} & 0.757^{b} \\ \text { Monkey 4 } & 0.682^{b} & 0.589^{b} & 0.598^{b} \\ \text { Monkey 5 } & 0.658^{b} & 0.689^{b} & 0.685^{b}\end{array}$

${ }^{a} p<0.05,{ }^{b} p<0.01$ (2-tailed $t$ test). cell having twice as large a movement-direction range during any particular epoch compared with a second cell of the same response type may also show twice as large a load-dependent change in activity. This factor contributed partly to the correlation in Figure $17 \mathrm{~A}$ since similar, but smaller, correlations were found when the analysis was repeated for each of the 4 cell classes separately (data not shown). To try to account for this confounding factor, the following correction was made. One can define a position/movement index as a measurc of the relative contribution of the cell to posture vs movement (see Materials and Methods). One can likewise define a load/movement index as a measure of the relative contribution of the cell to load compensation versus movement. The correlation between the position and load-compensation responses of cells is improved considerably when normalized for the movement-direction range of each cell in this way, especially that during the RT epoch (Fig. 17B; Table 6B). Thus, cells with small position/movement indices, i.e., which made a relatively smaller contribution to different postures than to different directions of movement when no load was attached to the arm, also tended to play a relatively smaller role in compensation for the tonic inertial loads, compared with cells with large position/movement indices.

Another factor that shows a relation to strength of load effects is microstimulation threshold. In 3 monkeys with sufficient microstimulation data, therc was a negative relation between the microstimulation threshold and the load/movement index of each cell (Fig. 18A). Cells with larger load/movement indices tended to be located at sites at which thresholds were lower than for cells with small load/movement indices. In all cases, this relation was significant ( $t$ test, $p<0.01$ ), but correlation coefficients were low $(0.35-0.5)$. In parallel with the microstimulation results, we found that the tonic and phasic-tonic cells were typically large-amplitude spikes recorded at intermediate depths in the cortex (Fig. 18B). The phasic cell types were often small-amplitude spikes recorded outside of the large-cell zone. However, at this point, the sample of lesion sites is too small 
A

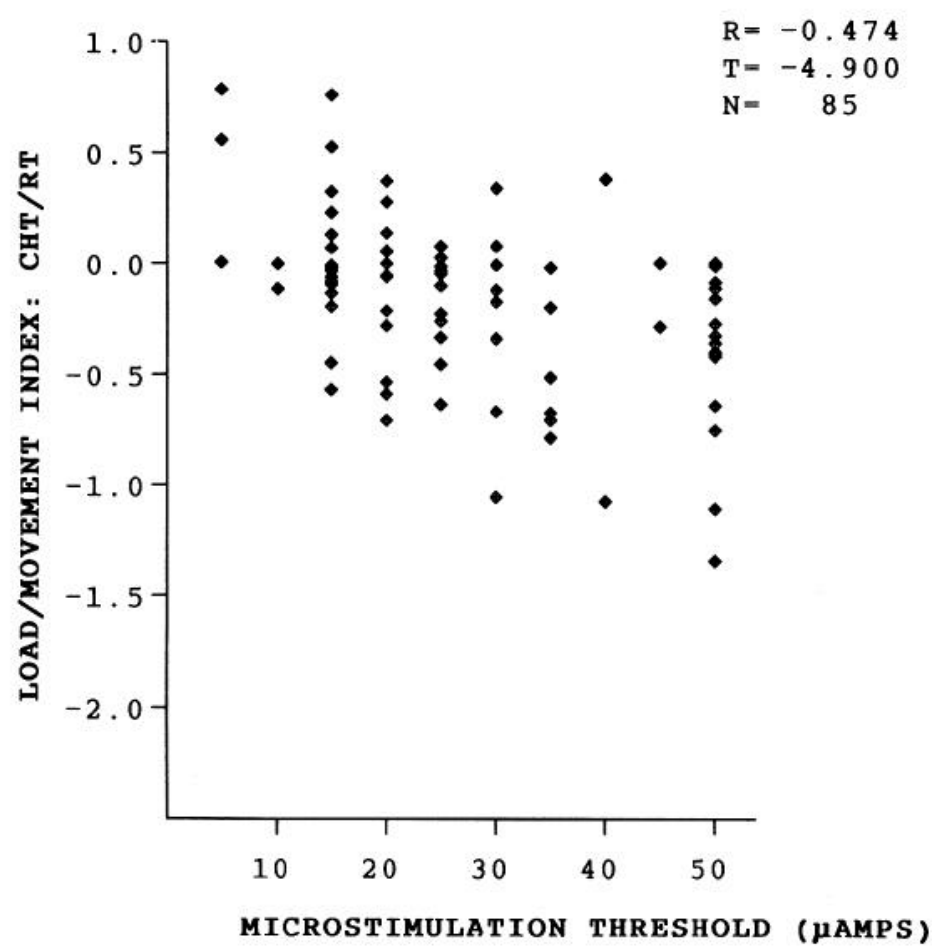

B

Figure 18. A, Negative correlation between microstimulation threshold and sensitivity to loads. Cells whose load-direction range during CHT
was large compared to their movement-direction range during RT (load/movement index $>0.0)$ tended to be located at sites of low microstimulation threshold. B, Photomicrograph of a $30 \mu \mathrm{m}$ frozen section of the motor cortex, indicating the site in lamina V near the junction of lamina VI (solid arrow; $6 \mu \mathrm{A} \times 10 \mathrm{sec}$ lesion) at which a phasic-tonic cell with a large load-direction range was recorded. The hollow arrow indicates a smaller lesion marking the entry point of the electrode. $C S$, central sulcus. Scale bar, $1 \mathrm{~mm}$.

to make any firm statements as to the cytoarchitectonic distribution of different cell types.

\section{EMG recordings}

Electromyographic activity patterns of muscles of the shoulder and shoulder girdle under these task conditions were qualitatively similar to those of motor cortex cells. Figure 19 shows the behavior of the left posterior deltoid muscle of one monkey. The muscle underwent continuously graded changes in activity with the direction of movement in the control block and continuously graded changes in activity with different directions of load. Most other muscles tested (acromiodeltoid, trapezius, rhomboids, infraspinatus, subscapularis, teres major, triceps longus, latissimus dorsi, pectoralis) also showed large tonic activity changes with loads. Single motor units recorded in these muscles showed similar properties. The cleidodeltoid and supraspinatus muscles were primarily phasic in the task. They showed large load-dependent changes in their movement-related activity but modest or no tonic activity changes associated with limb posture or loads. The 2 heads of the biceps and the lateral and medial heads of the triceps were relatively inactive under any conditions in this task.

\section{Discussion}

This study compared the effects of 2 spatial parameters, direction of movement and direction of applied loads, on the discharge of proximal arm-related motor cortex neurons during

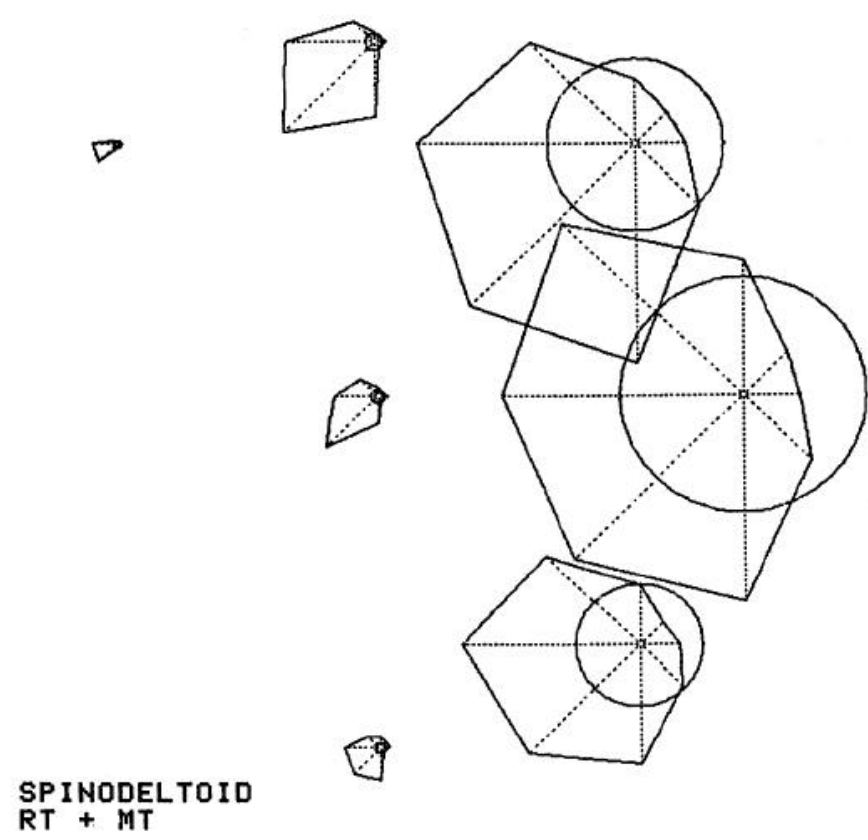

Figure 19. Activity of the spinodeltoid muscle of the left arm, under all conditions of movement and load. Note that this figure has not been mirror-image transformed to the right arm, unlike cell data collected with the left arm. 
whole-arm reaching movements. Four principal observations were made. First, many neurons related to movements of the shoulder joint and girdle showed similar continuously graded changes in discharge as a function of the direction of both parameters. Second, the arm-movement and load-compensation processes were spatially coupled, since each cell's load axis was approximately opposite its preferred movement direction. Third, the discharge variations caused by these 2 spatial parameters were approximately additive. This relation was most evident for the summed activity of the sample population. Fourth, there was a broad range in the degree of sensitivity of cells to loads. This sensitivity was correlated with other cell properties, including the temporal pattern of discharge during movement, in particular the range of discharge variation associated with active maintenance of different arm postures, as well as the microstimulation threshold at the site of recording.

These findings on the cortical control of the shoulder joint in a multiple degree-of-freedom task show a number of parallels with previous studies using more limited ranges of movement of distal joints (Evarts, 1968, 1969; Humphrey et al., 1970; Humphrey, 1972; Smith et al., 1975; Conrad et al., 1977; HeppReymond et al., 1978; Thach, 1978; Cheney and Fetz, 1980; Hoffman and Luschei, 1980; Evarts et al., 1983; Fromm, 1983a, b). While there may exist differences in the neural systems controlling proximal and distal limb movements (Phillips and Porter, 1964; Clough et al., 1968; Lawrence and Kuypers, 1968a, b; Kuypers and Brinkman, 1970; Humphrey, 1979; Lemon, 1979), there are also many similarities in the neural mechanisms at the level of the motor cortex.

\section{Variation of cell activity with direction}

The variation of discharge with the direction of loads demonstrates that the activity of many shoulder-related cells parallels changes in the torque trajectory required for the compensation of loads in different directions, as originally described by Evarts $(1968,1969)$. While their discharge covaries with output torques, we do not mean to imply that these motor cortex cells are specifically signaling the level of torque output per se. Exactly what aspects of muscle activity are controlled by the CNS and how this control function is encoded in motor cortex activity have yet to be determined (Stein, 1982). We emphasize that we will use "torque" here strictly as a convenient descriplive term to imply this apparent relation to movement dynamics since it is the final mechanical outcome of any process controlling movement dynamics.

A vector notation showed that the pattern of activity of the population formed a signal appropriate to compensate for the loads during the load blocks. This analysis suggests that the activity of these neurons can be described in terms of a vectorial signal related to movement dynamics, oriented at a particular angle across the joint. Each ccll makes a contribution, at its particular angle across the joint, to the net torque required at the shoulder to compensate for external loads over a broad range of directions. The strength of this contribution to movement dynamics is continuously graded as a function of the difference between the spatial orientation of the cell's torque output angle and the direction of the required net torque vector. The required net torque output results from the summation of all of the graded single-cell vectorial contributions.

The orientation of each cell's load axis and preferred direction are coupled, tending to be in opposite directions. Cell activity during movement in the unloaded condition shows continuously graded changes centered on the preferred direction, and a vectorial notation shows that the pattern of activity of the population in the control block corresponds to the direction of movement. These similarities between arm-movement and loadcompensation relations are consistent with the idea that cell activity during unloaded movements is likewise related to movement dynamics, representing the signal required to overcome gravity and the internal loads imposed by the inertia of the arm, and the viscoelastic properties of the muscles and joints. Since the preferred directions of different cells are distributed uniformly in both 2-dimensional (Georgopoulos et al., 1982) and 3-dimensional tasks (Georgopoulos et al., 1986, 1988; Schwartz et al., 1988), the direction of these single-cell output vectors is presumably distributed uniformly in all directions across the shoulder joint.

The vectorial representation of cell activity can be interpreted in terms of muscle activity (see also Georgopoulos et al., 1983, 1988; Schwartz et al., 1988). Most of the muscles recorded in the task showed directional propertics for movements and loads that were qualitatively similar to those of the cells. The qualitative similarity of the movement-direction and load-direction relations of many cells supports the hypothesis that they are alternate expressions of the same function, the control of muscle activity exerted across the shoulder joint at an angle that is unique for each cell. The direction of a cell's torque output vector may therefore be determined by the muscle(s) to which the activity of the cell is correlated, and thus the angle across the shoulder that the resultant muscular tension is exerted. This angle determines both the preferred direction and load axis of the cell.

Mussa-Ivaldi (1988) has done a theoretical analysis of how the signal controlling the activity of a muscle would vary with the direction of movement at the shoulder. This analysis predicted that the signal should vary sinusoidally, as we have obscrved. He noted that this prediction would hold irrespective of what aspect of muscle activity is controlled by the signal. He also noted that these continuously graded control signals would result whether motor cortex cells controlled single or multiple muscles.

Our experiment did not directly address this specific question, and our results do not provide any conclusive evidence as to which muscle(s) the activity of a given cell may be related. However, anatomical (Shinoda et al., 1981) and physiological evidence (Asanuma et al., 1979; Fetz and Cheney, 1980; Buys et al., 1986) indicates that a single cell related to distal-arm movement can modulate the contractile activity of several muscles simultaneously. Given that the relative density of corticospinal terminations on spinal interneurons versus spinal motoneurons is greater for the proximal arm than for the distal arm (Kuypers and Brinkman, 1970), it is even less probable that proximal-arm cortical neurons are related to single muscles. It is likely more appropriate to describe their behavior in terms of a muscle field (Fetz and Cheney, 1980) or equivalent muscle (Mussa-Ivaldi, 1988), that is, a functional unit comprised of several muscles upon which the cell exerts a modulatory influence. The spatial orientation of the torque output vector controlled by a cell would depend on the relative weighting of the cell's influence on each muscle and the rcsultant vectorial summation of the single-muscle torques across the shoulder joint. Therefore, unless the weighting for one muscle is substantially greater than for that of the other muscles in its field, the single- 
cell vector would be at an arbitrary angle, not necessarily corresponding to that of any particular muscle. This is indirectly corroborated by the observation that the distribution of preferred directions is rather uniform, without a tendency to cluster about a fixed number of directions corresponding to the preferred directions of the various shoulder muscles. This suggests that cells are signaling aspects of movement dynamics at arbitrary angles across the shoulder joint, which are converted to appropriately weighted muscle activities by the distribution of terminals in spinal interneuronal and motoneuronal pools.

This interpretation could be tested by defining the identity and relative weighting of a cell's target muscles, determining the direction of torque output and resulting arm movement expected by their contraction, and then comparing this to the cell's preferred direction and load axis. Spike-triggered averaging (Fetz and Cheney, 1980) is probably inadequate for determining a cell's muscle field in this situation since it is effective primarily when monosynaptic corticomotoneuronal connections exist. Single-pulse microstimulation (Cheney and Fetz, 1985) might bc morc appropriatc for shoulder-related cells. A sophisticated understanding of the complex biomechanics of the skeletomuscular apparatus of the shoulder joint and girdle is also required to translate the predicted pattern of activity of a cell's muscle field into patterns of torque and movements. This is required to test whether the intensity of cell discharge better fits the pattern of changes in torques, muscle contractile activity, or other factors.

This discussion emphasizes the important role of the motor cortex as a processor of spatiomotor information. Many motor cortical neurons are evidently involved in the transformation between the direction of movement and the direction and level of output torques. For each cell, the mapping between the multidimensional spatial domain and the scalar torque output domain is approximated well by a simple cosine function of the direction of each cell's output torque vector relative to the net required torque. An important further advance would be to understand how this mapping function varies with the starting posture of the arm (Georgopoulos et al., 1984a; Kettner et al., 1988).

This study does not resolve how the CNS solves the inverse dynamics problem (Hollerbach, 1982; Hogan, 1985, 1988), that is, the calculation of the movement dynamics given knowledge of the desired kinematics. Neither does it clarify whether motor behavior is represented in the motor cortex in terms of endpoint trajectories (hand paths), end-point forces or torques, joint trajectories or torques, neuromuscular mechanics, or other possible coordinate systems. Evidence that the CNS plans and represents multijoint movements in terms of most or all of these alternatives has been obtained (Feldman, 1966; Polit and Bizzi, 1979; Bizzi et al., 1984; Hogan, 1984, 1985, 1988; Atkeson and Hollerbach, 1985; Flash and Hogan, 1985; Soechting and Terzuolo, 1988). We have demonstrated that the patterns of discharge of cells related to shoulder joint movement obey fairly simple relations when described in terms of movement direction (hand paths), and many also show a corresponding relation to load direction (end-point forces or torques). However, MussaIvaldi's analysis (1988) shows that the transformation between these coordinates and a coordinate framework based on muscle contractile state variables or ncuromuscular mechanics is also a cosine function similar to that which we have observed.

A tacit assumption of this discussion is that all motor cortex activity is related exclusively to movement dynamics or even to the specific control of muscle contractile activity. The validity of this assumption will be examined further in a later section.

\section{Additivity of movement- and load-related cell activity}

We measured the activity associated with movement of the limb and pendulum without external loads, as well as the changes in discharge associated with compensation for loads prior to and during movement. There was a strong correlation, with a slope near 1.0 , between the size of the external load-dependent variation observed during CHT for each cell and that in all subsequent epochs of the trial. This indicated that the inertial loads caused changes in cell discharge of approximately constant intensity throughout all epochs of the trial. The major effect of the loads, therefore, was to set an overall tonic level or "offset" of activity, upon which was superimposed a nearly constant movement-related signal. This was particularly true when considering the behavior of the sample population, where the activity associated with any combination of movement direction and load direction was approximately the linear sum of the movement-related activity without external loads and the change in tonic rate prior to movement caused by the external loads. There remained only a small load-dependent variation in activity during movement (Fig. 14) which was not accounted for by this simple relation.

A biomechanical analysis done by Atkeson and Hollerbach (1985) is relevant. They calculated the torques required at each joint to move an arm with a load held in its hand, a situation analogous to that in our task. They demonstrated that the net torque at each joint was the sum of the torque required to move the arm and its mass without the load and the torque required to move the load at the end of a massless "phantom" arm. Each of these torques can be divided into 2 components, one to maintain a posture and compensate for gravity and one to move the mass of the limb or load at the desired velocity:

$$
\tilde{\tau}=\tau \underset{\text { gravity }}{\operatorname{arm}}+c^{2} \tau \underset{\text { drive }}{\operatorname{arm}}+r \tau \text { gravity } \text { load }+c^{2} r \tau \text { load, }
$$

where $c$ is the velocity of movement, and $r$ is a scaling factor, in this case representing the mass of the load relative to that of the arm plus pendulum. The additivity of the torque terms could therefore account for the additivity of the cell responses. Different components of the neural activity seen in Figure 8 can be associated with these terms. The tonic activity during $\mathrm{CHT}$ in the control block accounts for the first term. The control movement-related curve reflects the second term. The variation in tonic rate during $\mathrm{CHT}$ under load reflects the effect of the third term. The residual curvature of the movement $\times$ load response plane after subtraction of the CHT load-related curve (Fig. 14) presumably reflects the fourth term, the extra torque required to move the load.

This residual curvature is small, indicating that the fourth term is relatively small in this task situation, compared with the other 3 terms. This is reasonable when one considers that the weight represents a significant gravitational load of 2.43 or $3.42 \mathrm{~N}-\mathrm{m}$. This requires the monkey to exert $0.81 \mathrm{~N}-\mathrm{m}$ or 1.14 $\mathrm{N}-\mathrm{m}$ isometric output torque to compensate while holding at the center, due to the 3:1 mechanical advantage of the pendulum. However, the effective mass of the load $(83.3$ or $116.7 \mathrm{gm}$ ) is small compared with that of the arm plus pendulum. Moreover, the mechanical advantage of the pendulum for application of the acceleration torque required to displace the load is in- 
creased to 9:1 since the distance the weight is displaced and its peak velocity are only $1 / 3$ of that of the hand at the distal end of the pendulum. The monkeys typically achieved peak hand velocities of $0.3-0.4 \mathrm{~m} / \mathrm{sec}$ after $0.2 \mathrm{sec}$, which require average acceleration torques of less than $0.1-0.15 \mathrm{~N}-\mathrm{m}$ to displace the weight. As a result, the drive term for the load is substantially smaller than that to hold the weight against gravity or to move the arm and pendulum without loads. Thus, much of the loadrelated behavior of our sample population may reflect the mechanical properties of the manipulandum.

Of course, relating the cell activity in Figures 8 and 14 to the movement dynamics must be done with caution. In generating those figures, cach ccll in the population was given a weighting proportional to its discharge frequency. However, this may not correspond to the relative size of the torque output that each cell generates.

Another reason that these cell discharge frequency curves cannot be directly equated with the torques in the task is that the force/discharge relation for many cells is sigmoidal, and so is linear over only part of its range (Cheney and Fetz, 1980; Evarts et al., 1983). At the extremes of this range, cell discharge tends to asymptote at maximum and minimum frequencies that vary from cell to cell. Evidence of this effect was seen in the activity of many cells.

For instance, one common observation was a saturation of activity at a maximum frequency when confronted with loads near their load axis (Fig. 12C). Presumably, the movementrelated activity in the control block was already approaching the maximum discharge rate for that cell. When the tonic discharge increase involved in the load compensation process shifted the overall activity of the cell nearer its saturation point on the sigmoidal force/discharge curve, additivity of the load-compensation and movement processes could not be realized.

It was also common to observe cells showing a reduction in movement-related response caused by "assisting" loads, opposite to the cell's load axis, that was much greater than the reduction in premovement tonic rate (Fig. $12 B$ ). In this situation, one can assume that the load shifted the cell's tonic discharge rate to the lower asymptotic end of its force/discharge curve. For linearity to be maintained, the tonic rate of the cell would have had to have been driven below its inherent basal tonic rate and would have had to have been a "negative" rate for those cells whose tonic discharge was completely eliminated by the assisting loads. This would explain why the CHT loadrelated curve was not symmetric about the control CHT tonic rate, showing larger increases for opposing loads than decreases for assisting loads. This would also contribute to the finding that the movement direction-related discharge variation of the population decreased under assisting loads (Fig. 13B). The performance of movements opposite to the preferred direction, coupled with the presence of assisting loads, would both drive the cells toward their minimal discharge rate, flattening out the tails of the movement-related curve.

A related point is that our search procedure was biased toward cells with directionally tuned activity during movement in the no-load condition. These cells may be low-threshold neurons that generate small output torques (Evarts et al., 1983). There may exist cells with elevated torque thresholds (Hepp-Reymond et al., 1978) which are relatively inactive in the no-load condition but which would become active and generate large torques under the appropriate conditions of load and movement. Such cells, however, are evidently rare (Cheney and Fetz, 1980; Fromm and Evarts, 1981; Evarts et al., 1983).

Another complication arises from the inertial loads used in the task. The movement velocities in the task were moderate to fast (peak velocities, $200-400 \mathrm{~mm} / \mathrm{sec}$; duration, $250-500$ msec) but not maximal or "ballistic." Nevertheless, there will be some transient changes in the loading of the limb between movements along the direction of load, which raise and lower the weight against gravity, and those perpendicular to the direction of load, which do not raise or lower it.

The complex geometry and biomechanics of the limb are also important potential sources of nonlinearities. The movements involve large changes in shoulder angle, with concomitant changes in muscle lengths, moment arms, and angles of line of pull. The arm also has a non-uniform stiffness which varies with arm posture (Mussa-Ivaldi et al., 1985). Certain features of cell activity in the task, such as the findings that the load axis is not always exactly opposite to the preferred direction and that the load-related vector sums of cell activity are not always exactly opposite the direction of load, may be explained by these biomechanical properties. This will be examined in detail in a subsequent paper.

\section{Sensitivity to loads}

A major observation is that the motor cortex sample population formed a continuum, from cells that were directional for movement and strongly influenced by loads to cells that were strongly directional for movement yet relatively insensitive to loads. The position of a particular cell along this continuum appeared partly dependent on the relative strength of its relation to movement versus maintenance of different limb postures.

If it is assumed that all motor cortex activity encodes parameters of movement dynamics, then cells that did not show much load sensitivity are presumably making a much greater contribution to the torques required to overcome the internal loads presented by movement of the arm in the gravity ficld than to the torques required to compensate for the experimentally imposed external loads. Several explanations could be proposed to account for this.

The difference in cell properties may simply reflect a threshold effect. Some cells may have torque output thresholds that are sufficiently high that they are recruited only when the system generates the torques required to move the arm. The torques required to hold the limb in different postures or to compensate for the loads are subthreshold, and so the cells appear to be phasic and load-insensitive in the task. These cells would begin to show load-related changes in tonic rate if load magnitude was increased. Previous studies do not favor this possibility since most cells show force/discharge sensitivity at low force levels, and cells with high force thresholds are uncommon (Cheney and Fetz, 1980; Evarts et al., 1983). For a couple of load-insensitive cells, we applied a larger load $(500 \mathrm{gm})$, but this did not radically alter their behavior in the task.

Another possibility is that the cells with modest load-direction sensitivity may be related functionally to shoulder muscle fields that are coactive with the limb movements but do not contribute to the tonic compensation for the inertial loads. Most shoulder joint/girdle muscles showed large changes in tonic EMG activity with limb posture and load direction, which does not support this possibility. The cleidodeltoid and supraspinatus muscles were mainly phasic in the task and showed relatively little tonic 
EMG activity related to posture or loads. They did, however, show large changes in their phasic movement-related discharge under different load conditions, which was not characteristic of most cells with low load sensitivity. Nevertheless, this factor cannot be discounted.

The assumption that all motor cortex activity signals movement dynamics may not be correct, however. An alternative explanation is that the motor cortex generates signals about movement kinematics, as well as dynamics. Furthermore, the activity of any given cell could be a weighted combination of both types of movement information, the degree of relative weighting varying from cell to cell. Cells at the 2 extremes of the load-sensitivity continuum could be regarded as functionally distinct cell types, signaling primarily movement dynamics (Figs. $6,7 \mathrm{~A}$ ) versus kinematics (Fig. $7 \mathrm{C}$ ). Cells with large tonic discharge components related to different arm postures were more likely to show large tonic rate changes with different loads than were cells with a more strictly phasic relation to movement. These different temporal patterns may therefore reflect differing degrees of processing of information related to movement kinematics versus dynamics between phasic and tonic cell types. Similar differences have been described previously between corticospinal and corticorubral cells (Fromm, 1983b).

Also consistent with this explanation is the preliminary evidence of some degree of spatial segregation of the phasic versus tonic cell types. The tonic and phasic-tonic cells tended to be concentrated in the intermediate and deep laminae of the cortex in the anterior bank of the sulcus, where large-amplitude spikes were recorded and microstimulation thresholds were lowest (Asanuma and Rosén, 1972; Kwan et al., 1978). The phasic cells were usually outside of this zone, at sites of higher microstimulation thresholds. Cheney and Fetz (1980) made similar observations in a study of cells related to wrist movements, which projected directly onto spinal motoneurons. These corticomotoneuronal $(\mathrm{CM})$ cells showed tonic activity changes with different wrist postures and different external loads or output force levels. In contrast, they found that some non-CM cells were phasic and were encountered in cortical regions surrounding the CM cells, not interspersed with them. They did not describe the load sensitivity of these phasic non-CM cells. However, their observations are consistent with ours of at least a partial segregation of cells with different temporal relations to movement. What has yet to be determined is whether the different cell types are concentrated in different zones or vertical columns within the cortex or in different laminae of the same column. Either possibility is tenable since microstimulation threshold varies with the distance from the central sulcus, as well as with lamina (Kwan et al., 1978; Weinrich and Wise, 1982). This question is currently under investigation.

The motor cortex contains several different cell populations receiving from and projecting to different parts of the CNS (Jones and Wise, 1977; Porter, 1982; Jones, 1986). There is no a priori reason to assume that their functional relation to movement is identical. Laminar differences in neuronal response properties is a principle of neocortical function that is already well established in sensory areas (Hubel and Wiesel, 1968; Whitsel et al., 1972; Dow, 1974; Poggio and Fischer, 1977; Hyvärinen et al., 1980; Sur et al., 1984). Likewise, it is possibly incorrect to describe the function of all motor cortex cells in terms of muscle activity, forces, torques, or other movement dynamics parameters. This may be appropriate only for certain cells, such as the corticospinal population. Confirmation that cells in different laminae or projecting to different CNS targets have different relations to movement would have important consequences for our understanding of overall motor cortex function.

\section{References}

Asanuma, H., and I. Rosén (1972) Topographical organization of cortical efferent zones projecting to distal forelimb muscles in the monkey. Exp. Brain Res. 14: 243-256.

Asanuma, H., P. Zarzecki, E. Jankowska, T. Hongo, and S. Marcus (1979) Projections of individual pyramidal tract neurons to lumbar motor nuclei of the monkey. Exp. Brain Res. 34: 73-89.

Atkeson, C. G., and J. M. Hollerbach (1985) Kinematic features of unrestrained vertical arm movements. J. Neurosci. 5: 2318-2330.

Bizzi, E., N. Accornero, W. Chapple, and N. Hogan (1984) Posture control and trajectory formation during arm movement. J. Neurosci. 4: 2738-2744.

Buys, E. J., R. N. Lemon, G. W. H. Mantel, and R. B. Muir (1986) Selective facilitation of different hand muscles by single corticospinal neurones in the conscious monkey. J. Physiol. (Lond.) 381: 529-549.

Cheney, P. D., and E. E. Fetz (1980) Functional classes of primate corticomotoneuronal cells and their relation to active force. J. Neurophysiol. 44: 773-791.

Cheney, P. D., and E. E. Fetz (1985) Comparable patterns of muscle facilitation evoked by individual corticomotoneuronal (CM) cells and by single intracortical microstimuli in primates: Evidence for functional groups of CM cells. J. Neurophysiol. 53: 786-804.

Clough, J. F. M., D. Kernell, and C. G. Phillips (1968) The distribution of monosynaptic excitation from the pyramidal tract and from primary spindle afferents to motoneurones of the baboon's hand and forearm. J. Physiol. (Lond.) 198: 145-166.

Conrad, B., M. Wiesendanger, K. Matsunami, and V. B. Brooks (1977) Precentral unit activity related to control of arm movements. Exp. Brain Res. 29: 85-95.

Dow, B. M. (1974) Functional classes of cells and their laminar distribution in monkey visual cortex. J. Neurophysiol. 37: 927-946.

Evarts, E. V. (1968) Relation of pyramidal tract activity to force exerted during voluntary movement. J. Neurophysiol. 31: 14-27.

Evarts, E. V. (1969) Activity of pyramidal tract neurons during postural fixation. J. Neurophysiol. 32: 375-385.

Evarts, E. V., C. Fromm, J. Kröller, and V. A. Jennings (1983) Motor cortex control of finely graded forces. J. Neurophysiol. 49: 11991215 .

Feldman, A. G. (1966) Functional tuning of the nervous system during control of movement or maintenance of a steady posture. III. Mechanographic analysis of the execution by man of the simplest motor tasks. Biophysics 11: 766-775.

Fetz, E. E., and P. D. Cheney (1980) Postspike facilitation of forelimb muscle activity by primate corticomotoneuronal cells. J. Neurophysiol. 44: 751-772.

Flash, T., and N. Hogan (1985) The coordination of arm movements: An experimentally confirmed mathematical model. J. Neurosci. 5: 1688-1703.

Fromm, C. (1983a) Changes in steady state activity in motor cortex consistent with the length-tension relation of muscle. Pflügers Arch. 398: 318-323.

Fromm, C. (1983b) Contrasting properties of pyramidal tract neurons located in the precentral or postcentral areas and of corticorubral neurons in the behaving monkey. In Advances in Neurology 39: Motor Control Mechanisms in Health and Disease, J. E. Desmedt, ed., pp. 329-345, Raven, New York.

Fromm, C., and E. V. Evarts (1981) Relation of size and activity of motor cortex pyramidal tract neurons during skilled movements in the monkey. J. Neurosci. 1: 453-460.

Georgopoulos, A. P., J. F. Kalaska, R. Caminiti, and J. T. Massey (1982) On the relations between the direction of two-dimensional arm movements and cell discharge in primate motor cortex. J. Neurosci. 2: 1527-1537.

Georgopoulos, A. P., R. Caminiti, J. F. Kalaska, and J. T. Massey (1983) Spatial coding of movement: A hypothesis concerning the coding of movement direction by motor cortical populations. In Exp. Brain Res. Suppl. 7: Neural Coding of Motor Performance. J. Massion, 
J. Paillard, W. Schultz, and M. Weisendanger, eds., Springer-Verlag. pp. 327-336.

Georgopoulos, A. P., R. Caminiti, and J. F. Kalaska (1984a) Static spatial effects in motor cortex and Area 5: Quantitative relations in a two-dimensional space. Exp. Brain Res. 54: 446-454.

Georgopoulos, A. P., J. F. Kalaska, M. D. Crutcher, R. Caminiti, and J. T. Massey (1984b) The representation of movement direction in the motor cortex: Single cell and population studies. In Dynamic Aspects of Neocortical Function, G. M. Edelman, W. E. Gall, and W. M. Cowan, eds., pp. 501-524, Wiley, New York.

Georgopoulos, A. P., A. B. Schwartz, and R. E. Kettner (1986) Neuronal population coding of movement direction. Sci. 233: 1416-1419.

Georgopoulos, A. P., R. E. Kettner, and A. B. Schwartz (1988) Primate motor cortex and free arm movements to visual targets in threedimensional space. II. Coding of the direction of movement by a neuronal population. J. Neurosci. 8: 2928-2937.

Hepp-Reymond, M.-C., U. R. Wyss, and R. Anner (1978) Neuronal coding of static force in primate motor cortex. I. Physiol. (Paris) 74. 287-291.

Hoffman, D. S., and E. S. Luschei (1980) Responses of monkey precentral cortical cells during a controlled jaw bite task. J. Neurophysiol. 44: 333-348.

Hogan, N. (1984) An organizing principle for a class of voluntary movements. J. Neurosci. 4: 2745-2754.

Hogan, N. (1985) The mechanics of multi-joint posture and movement. Biol. Cybernet. 52: 315-331.

Hogan, N. (1988) Planning and execution of multijoint movements. Can. J. Physiol. Pharmacol. 66: 508-517.

Hollerbach, J. M. (1982) Computers, brains and the control of movement. Trends Neurosci. 5: 189-192.

Hollerbach, J. M., and C. G. Atkeson (1987) Deducing planning variables from experimental arm trajectories: Pitfalls and possibilities. Biol. Cybernet. 56: 279-292.

Hubel, D. H., and Wiesel, T. N. (1968) Receptive fields and functional architecture of monkey striate cortex. J. Physiol. (Lond.) 195: 215243.

Humphrey, D. R. (1972) Relating motor cortex spike trains to measures of motor performance. Brain Res. 40: 7-18.

Humphrey, D. R. (1979) On the cortical control of visually directed reaching: Contributions by nonprecentral motor areas. In Posture and Movement, R. E. Talbot and D. R. Humphrey, eds., pp. 51-112, Raven, New York.

Humphrey, D. R., E. M. Schmidt, and W. D. Thompson (1970) Predicting measures of motor performance from multiple cortical spike trains. Science 170: 758-762.

Hyde, M. L., and J. F. Kalaska (1984) Movement vs. load direction interactions in area 4 activity. Soc. Neurosci. Abstr. 10: 738.

Hyvärinen, J., A. Poranen, and Y. Jokinen (1980) Influence of attentive behavior on neuronal responses to vibration in primary somatosensory cortex of the monkey. J. Neurophysiol. 43: 870-882.

Jones, E. G. (1986) Connectivity of the primate sensory-motor cortex. In Cerebral Cortex, Vol. 5, Sensory-Motor Areas and Aspects of Cortical Connectivity, E. G. Jones and A. Peters, eds., pp. 113-183, Plenum, New York.

Jones, E. G., and S. P. Wise (1977) Size, laminar and columnar distribution of efferent cells in the sensory-motor cortex of monkeys. $J$. Comp. Neurol. 175: 391-438.

Kalaska, J. F., and M. L. Hyde (1985) Area 4 and area 5: Differences between the load direction-dependent discharge variability of cells during active postural fixation. Exp. Brain Res. 59: 197-202.

Kalaska, J. F., R. Caminiti, and A. P. Georgopoulos (1983) Cortical mechanisms related to the direction of two-dimensional arm movements: Relations in parietal area 5 and comparison with motor cortex. Exp. Brain Res. 51: 247-260.

Kalaska, J. F., D. A. D. Cohen, and M. L. Hyde (1985) Differences in the spatial rclation betwcen movement direction-dependent and load direction-dependent activity changes in primate cortex areas 4 and 5. Soc. Neurosci. Abstr. 11: 1273.

Kalaska, J. F., T. Milner, and M. L. Hyde (1987) Primate motor cortex: Load compensation mechanisms and limb stiffnenss. Soc. Neurosci. Abstr. 13: 246.
Kettner, R. E., A. B. Schwartz, and A. P. Georgopoulos (1988) Primate motor cortex and free arm movements to visual targets in threedimensional space. III. Positional gradients and population coding of movement direction from various movement origins. I. Neurosci. 8: $2938-2947$.

Kuypers, H. G. J. M., and J. Brinkman (1970) Precentral projections to different parts of the spinal intermediate zone in the rhesus monkey. Brain Res. 24: 29-48.

Kwan, H. C., W. A. MacKay, J. T. Murphy, and Y. C. Wong (1978) Spatial organization of precentral cortex in awake primates. II. Motor outputs. J. Neurophysiol. 41: 1120-1131.

Lawrence, D. G., and H. G. J. M. Kuypers (1968a) The functional organization of the motor system in the monkey. I. The effects of bilateral pyramidal lesions. Brain 91: 1-14.

Lawrence, D. G., and H. G. J. M. Kuypers (1968b) The functional organization of the motor system in the monkey. II. The effects of lesions of the descending brain-stem pathways. Brain 91: 15-36.

Lemon, R. N. (1979) Short-latency peripheral inputs to the motor cortex in conscious monkeys. Brain Res. 161: 150-155.

Mardia, K. V. (1972) Statistics of Directional Data, Academic, London.

Mussa-Ivaldi, F. A. (1988) Do neurons in the motor cortex encode movement direction? An alternative hypothesis. Neurosci. Lett. 91: 106-111.

Mussa-Ivaldi, F. A., N. Hogan, and E. Bizzi (1985) Neural, mechanical and geometric factors subserving arm posture in humans. J. Neurosci. 5: $2732-2743$.

Phillips, C. G., and R. Porter (1964) The pyramidal projection to motoneurons of some muscle groups of the baboon's forelimb. Prog. Brain Res. 12: 222-242.

Poggio, G. F., and B. Fischer (1977) Binocular interaction and depth sensitivity in striate and prestriate cortex of behaving rhesus monkey. J. Neurophysiol. 40: 1392-1405.

Polit, A.,, and E. Bizzi (1979) Characteristics of motor programs underlying arm movements in monkeys. J. Neurophysiol. 42: 183-194.

Porter, R. (1982) Internal organization of the motor cortex for inputoutput arrangements. In Handbook of Physiology, Section 1, The Nervous system, Volume II, Motor Control, Part 2, V. B. Brooks, ed., pp. 1063-1081, Williams \& Wilkins, Baltimore.

Schwartz, A. B., R. E. Kettner, and A. P. Georgopoulos (1988) Primate motor cortex and free arm movements to visual targets in threedimensional space. I. Relations between single cell discharge and direction of movement. J. Neurosci. 8: 2913-2927.

Shinoda, Y., J. I. Yokota, and T. Futami (1981) Divergent projections of individual corticospinal axons to motoneurons of multiple muscles in the monkey. Neurosci. Lett. 23: 7-12.

Smith, A. M., M.-C. Hepp-Reymond, and U. R. Wyss (1975) Relation of activity in precentral cortical neurons to force and rate of force change during isometric contractions of finger muscles. Exp. Brain Res. 23: 315-332.

Snedecor, G. W., and W. G. Cochran (1980) Statistical Methods, Iowa State University Press, Ames, Iowa.

Soechting, J. F., and C. A. Terzuolo (1988) Sensorimotor transformations underlying the organization of arm movements in threedimensional space. Can. J. Physiol. Pharmacol. 66: 502-507.

Stein, R. B. (1982) What muscle variable(s) does the nervous system control in limb movements? Behav. Brain Sci. 5: 535-577.

Sur, M., J. T. Wall, and J. H. Kaas (1984) Modular distribution of neurons with slowly adapting and rapidly adapting responses in area $3 \mathrm{~b}$ of somatosensory cortex in monkeys. J. Neurophysiol. 51: 724744.

Thach, W. T. (1978) Correlation of neural discharge with pattern and force of muscular activity, joint position and direction of intended next movement in motor cortex and cerebellum. J. Neurophysiol. 41: 654-676.

Weinrich, M., and S. P. Wise (1982) The premotor cortex of the monkey. J. Neurosci. 2: 1329-1345.

Whitsel, B. L., J. R. Roppolo, and G. Werner (1972) Cortical information processing of stimulus motion on primate skin. J. Neurophysiol. 35: $691-717$. 